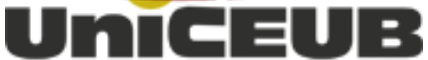 \\ Centro Unıversitárıo de Brasílıa \\ CENTRO UNIVERSITÁRIO DE BRASÍLIA - UnICEUB \\ FACULDADE DE CIÊNCIAS DA EDUCAÇÃO E DA SAÚDE - FACES \\ PROGRAMA DE INICIAÇÃO CIENTÍFICA
}

\author{
GUSTAVO PERREIRA MACÊDO
}

MEDIDOR RESIDENCIAL INTELIGENTE DE ENERGIA ELÉTRICA

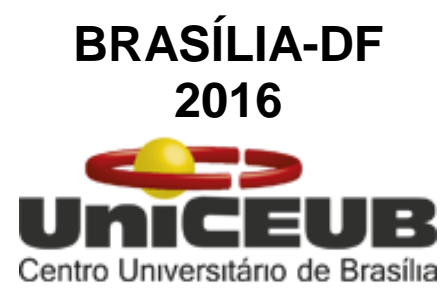




\section{MEDIDOR RESIDENCIAL INTELIGENTE DE ENERGIA ELÉTRICA}

Relatório final de pesquisa de Iniciação Científica apresentado à Assessoria de Pós-Graduação e Pesquisa pela Faculdade de Ciências da Educação e da Saúde - FACES (de acordo com a faculdade em que o aluno estiver matriculado) Orientação: Prof.MsC Luciano Henrique Duque.

\section{BRASÍLIA-DF}

2016 


\section{RESUMO}

Esse projeto propõe o desenvolvimento de um sistema para monitoramento e gerenciamento do consumo de energia elétrica em instalações residenciais, objetivando uma utilização mais racional, sem desperdícios desnecessários. Um circuito constituído por um microcontrolador e componentes eletrônicos discretos recebem e processam as informações de tensão, corrente, potência e fator de potência, transmitindo as informações para um computador via interface ethernet ou através de um display de cristal líquido. As informações podem ser armazenadas e visualizadas, formando um registro da energia consumida ao longo do tempo. Divisores de tensão, transformadores de corrente e amplificadores operacionais, coletam a tensão e corrente, enviando para o microcontrolador, que compara e processa estes dados, podendo enviar para um computador ou mesmo para um display. As informações processadas são tratadas por um software básico, que gera relatórios sobre as informações de consumo de energia elétrica. O Medidor residencial inteligente irá sinalizar ao usuário sempre que, sua meta de consumo mensal ou diário atingir $60 \%$ do valor estipulado, podendo também bloquear cargas em uso acima do previsto, definido pelo usuário ou pré- definido no medidor. A sinalização de indicativo de consumo acima do estipulado será feita através de um alarme sonoro, indicando ao usuário para que o mesmo faça uma redução de seu consumo.

Palavras-chave: gerenciamento de energia elétrica, monitoramento, desperdícios, micro controlador. 


\section{SUMÁRIO}

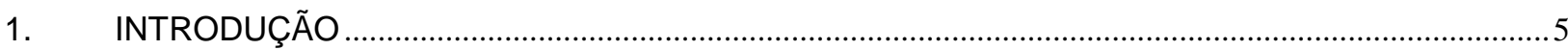

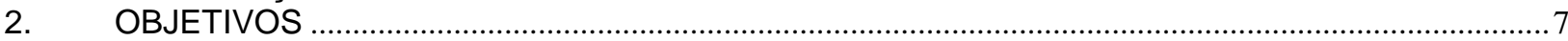

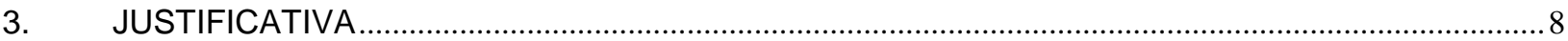

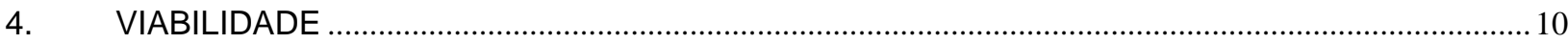

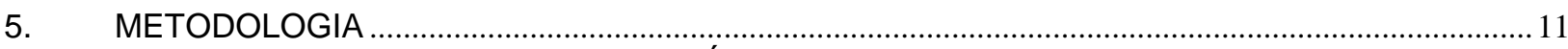

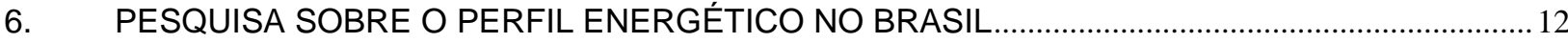

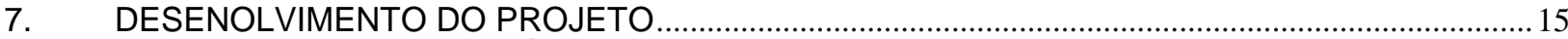

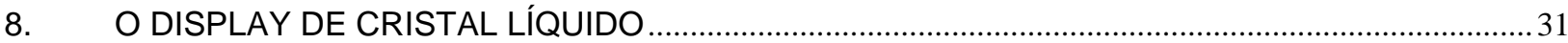

9. DESENVOLVIMENTO DO PROJETO MEDIDOR RESIDENCIAL INTELIGENTE..............................33

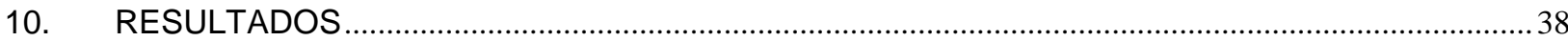

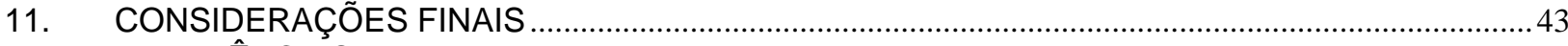

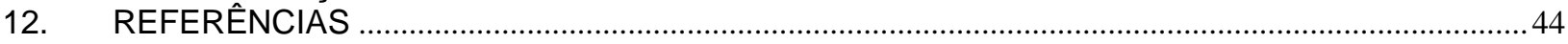




\section{INTRODUÇÃO}

A energia elétrica pode ser gerada através de diferentes fontes, no Brasil ela em sua grande maioria vem das usinas hidrelétricas, que utilizam as quedas d'água dos rios para gerar eletricidade. A energia elétrica é muito importante em nossas residências, porém o mais importante é utilizá-las de forma racional, sempre consumindo o necessário e assim estaremos contribuindo para preservação de nosso meio ambiente. O aumento do desperdício de energia elétrica implica obrigatoriamente no aumento da potência instalada de geração. Este aumento representa um custo elevado, tanto ambiental quanto em investimentos em equipamentos (MARTINS, 1999).

O Brasil hoje perde $16,5 \%$ de toda a energia elétrica produzida. Para tornar mais eficiente o aproveitamento da energia, seria preciso investir em duas frentes: programas de conscientização dos consumidores e a busca de processos industriais mais econômicos. $O$ produto proposto atua no auxílio e combate ao desperdício, apresentando como uma ferramenta excelente na contribuição aos programas de conscientização dos consumidores do governo federal.

Segundo o PROCEL, Programa de Combate ao Desperdício de Energia Elétrica, cerca de $25 \%$ da energia produzida no país é gasta em residências. O chuveiro é um dos maiores responsáveis pela alta do preço da conta no fim do mês. Tomar banhos curtos, apagar luzes ao sair dos aposentos, não deixar eletrodomésticos ligados, nem abrir a porta da geladeira sem necessidade são formas fáceis de economizar energia. O produto que propomos atua nesse contexto, possibilitando a medição, temporização e controle das cargas residências, auxiliando na redução do consumo e desperdícios desnecessários.

Segundo Al Gore (2006), uma das maiores desafios do século 21 é a preservação e recuperação do meio ambiente. Mais precisamente o impacto causado ao meio ambiente pelas atividades humanas. Sabe-se que é impossível deixar de impactar o meio ambiente, entretanto deve-se ter responsabilidade e tomar providências para que toda energia gerada seja usada da forma mais eficiente e racional possível. Portanto, será necessário dispor de ferramentas que possibilitem o gerenciamento da energia gasta pelos equipamentos tão necessários à vida 
moderna, de modo a obter o máximo rendimento com um mínimo impacto ao meio ambiente, visando sempre o desenvolvimento voltado para sustentabilidade.

Este projeto propõe um sistema para o gerenciamento do consumo de energia de uma residência, onde os próprios usuários podem visualizar seu consumo e até mesmo estipular suas metas de consumo. O sistema consiste em medir a tensão, corrente e fator de potência do consumidor, coletando e armazenando esses dados, e podem ser transmitidos e visualizados no próprio medidor ou via computador. De posse dessas informações, então serão tomadas as decisões corretas, no tempo certo, com o intuito de racionalizar o gasto com energia.

No projeto do medidor residencial inteligente é previsto um dispositivo de controle automático de cargas, sempre que o tempo de funcionamento da carga exceder o limite estabelecido será enviando comandos para seu desligamento. 0 próprio usuário poderá selecionar qual seu consumo mensal ou diário, que serão controlados por sinalizações sonoras, sempre que o consumo atingir o valor definido. A meta de consumo diário ou mensal será baseada na quantidade de cargas do ambiente do usuário e definida no software do medidor. Para gerenciar de forma eficiente o consumo residencial, faz-se necessário desenvolver um medidor inteligente com várias opções de visualização e entrada de dados. No Brasil existem várias políticas destinadas a apoiar a redução do consumo de energia elétrica. Destaca-se o PROCEL (Programa Nacional de Conservação de Energia Elétrica) cuja política é promover a racionalização da produção e consumo de energia elétrica, nesse contexto, o projeto proposto poderá colaborar com o programa (BRASIL, 1999).

Nesse cenário, o projeto proposto tem por objetivo agregar valores na área de gerenciamento e monitoração de consumo de energia elétrica residencial, agindo em prol de um desenvolvimento sustentável, utilizando sempre o necessário, sem comprometer as gerações atuais e futuras. O Medidor Residencial Inteligente de Energia também se apresenta como uma oportunidade para controle de consumo e gastos de energia e com possibilidade de identificação de possíveis desperdícios de energia elétrica provocados por uma instalação elétrica 
inadequada ou mesmo equipamentos elétricos ou eletrônicos que apresentarem fuga de correte.

\section{OBJETIVOS}

Objetivo geral: $O$ nascimento e a evolução de sistemas inteligentes para residências deu-se inicialmente a partir da utilização de sistemas automatizados em indústrias para agilizar os processos produtivos e minimizar custos relacionados ao consumo de energia elétrica, passando a automação predial e chegando então à automação residencial.

Este projeto tem por objetivo agregar valores na área de gerenciamento $\mathrm{e}$ monitoração de consumo de energia elétrica residencial, agindo em prol de um desenvolvimento sustentável, utilizando sempre o necessário, sem comprometer as gerações atuais e futuras. Pesquisar e estudar o comportamento do consumo de energia elétrica residencial, apresentando um modelo de protótipo adequado para seu gerenciamento e monitoração do consumo de energia.

\section{Objetivos específicos:}

- Medir corrente, tensão, potência, fator de potência e energia;

- Contribuir na prevenção e redução do desperdício de energia elétrica residencial;

- Desenvolver modelos de relatórios de consumo simples e de fácil entendimento do usuário residencial;

- Monitorar o consumo de energia elétrica como base na família de micro controlador PIC (Programmable Interface Controller);

- Listar as informações de tensão, corrente, potência e energia em múltiplos dispositivos, em especial: Diplay de Cristal Líquido (LCD), computador e celular;

- Elaborar uma interface para ethernet para que o usuário possa acessar relatórios via internet;

- Desenvolver um software básico para tratar as medidas de tensão, corrente, potência e fator de potência, gerando relatórios de consumo diário, mensal ou anual;

- Redigir um manual técnico de operação e instalação do medidor;

- Permitir o controle de cargas elétricas tais como: chuveiro, lâmpadas, aquecedores etc.; 
- Estimar a redução do consumo com a utilização do medidor e através de estatísticas mostrar a economia anual de energia em relação a sua geração.

\section{JUSTIFICATIVA}

No cenário atual, o governo brasileiro entre 2009 e 2011 (início) reduziu impostos para impulsionar a economia em função da crise mundial. Uma das medidas foi à redução dos preços dos eletrodomésticos e eletroeletrônicos, o IPI (Imposto sobre produtos industrializados). Essa redução provoca o aumento da procurar pelos eletrodomésticos e eletroeletrônicos, aquecendo a economia e aumento o consumo de energia elétrica. É importante também resultar que as estratégias de vendas promovem a compra de aparelhos eletrodomésticos em todas as classes sociais, tanto as mais abastadas quanto às de menor poder aquisitivo, as mais cultas e as menos cultas, aumentando o consumo de energia. Outro fator importante é o aumento do poder aquisitivo da população brasileira que cresceu nos últimos oito anos, contribuindo para o aumento do consumo de eletrodomésticos e eletrônicos.

$\mathrm{Na}$ expectativa de chamar a atenção do cliente para os novos eletrodomésticos, as fabricas vem produzindo equipamentos com inovações que permitam ligar e desligar através de controle remoto. Este dispositivo exige que 0 equipamento fique em standby, o que significa que o mesmo fica consumindo energia sem estar sendo usado. Os consumidores residenciais por não terem conhecimento do valor que representa o consumo de energia elétrica do aparelho em standby, não se importam com este fator.

Ainda vale lembrar que o desperdício de energia elétrica no Brasil é grande. Para se ter uma idéia, um estudo do potencial de economia de energia elétrica realizado pela Coppe/UFRJ, a pedido da Eletrobrás e do Programa Nacional de Conservação de Energia Elétrica (Procel), identificou que na classe residencial de consumo, por exemplo, há um potencial de redução de aproximadamente 15\%. Em números absolutos, a economia poderia chegar a US\$2,5 bilhões (cerca de $\mathrm{R} \$ 4$ bilhões) por ano se o País usasse todo o seu potencial de utilização eficiente de energia, afirma estudo do Banco Mundial (BID). Segundo o BID, se a eficiência energética não melhorar no País, isso poderá acelerar as conseqüências para o meio ambiente, já que o consumo de energia está associado a uma 
alta emissão dos chamados gases geradores do efeito estufa (GEE), principalmente considerando a atual matriz energética nacional (IBGE,2010).

A medição da energia elétrica ativa $(\mathrm{kWh})$ energia que realiza trabalho, por exemplo, energia térmica e luminosa, representa do ponto de vista econômico, uma das mais importantes medições elétricas realizadas nos sistemas de distribuição de energia, pois através de uma medição precisa é possível avaliar qual o impacto gerado pelo aumento da demanda e seu desperdício. Basicamente, os medidores de energia elétrica ativa podem ser classificados quanto ao número de elementos/fios, quanto ao tipo de ligação à carga (diretos e indiretos), e quanto a sua característica construtiva, podendo ser eletromecânicos, eletrônicos ou mistos.

Nesse contexto, entende-se que analisar o comportamento do consumo de energia elétrica através dos órgãos de pesquisas, especificamente o EPE (Empresa de Pesquisa Energética) é importante para o traçado do perfil. Esse perfil permitirá auxiliar no traçado das metas de energia consumida pelos usuários residenciais, gerando perfis de consumos no sistema de medição residencial, controlado pelo usuário. O Medidor residencial inteligente proposto nesse estudo é alimentado pelas informações de perfis de consumo e metas prédefinidas ou definidas pelo usuário. Os medidores atuais visam apenas à medição e não incluem o controle remoto das cargas elétricas.

Portanto, o medidor proposto nesse projeto, visa medir : tensão, corrente, potência e energia, permitindo o controle do comportamento das cargas através de desligamento automático, redução de potência e luminosidade quando necessário, conforme limites estabelecidos pelos princípios de uma utilização racional e eficiente da energia elétrica, evitando desperdícios desnecessários.

Não foi encontrado um projeto de medidor que englobe o princípio de funcionamento e o desenvolvimento de um dispositivo com essas facilidades, no entanto é notória a relevância do tema no meio acadêmico, e podemos perceber a preocupação da mídia, dos consumidores e da indústria, pois novos produtos estão chegando ao mercado tendo a conservação e a otimização do consumo de energia elétrica como grande atrativo. O projeto ainda preza por uma 
preservação do meio ambiente, através da conscientização da redução de consumo elétrico, auxiliado pelo medidor residencial de energia elétrica proposto.

\section{VIABILIDADE}

Para viabilizar o desenvolvimento do medidor residencial de energia elétrica proposto, basicamente é necessário:

- Analisar o comportamento de consumo residencial de energia elétrica emitidos pelo EPE (Empresa de Pesquisa Energética);

- Medir Tensão, corrente, potência e fator de potência;

- Desenvolver um software para analisar e coletar as medições de propostas no item acima;

- Estimar a redução do consumo de energia elétrica com a utilização do medidor proposto.

Inicialmente deve-se determinar o comportamento do consumo estatístico de energia elétrica, com o objetivo de traçar o perfil de consumo a ser inserido no software do medidor. Em seguida iniciar o esboço do projeto, verificando quais os materiais necessários, tais como:

- Componentes eletrônicos;

- Instrumentos de medidas;

- Software para desenvolvimento de circuito impresso;

- Gravadores de micro controlador da família PIC;

- Mão de obra para viabilizar o projeto teórico e o protótipo.

Após desenvolver o circuito eletrônico, as interfaces de visualização e transporte das informações de medidas, são analisadas por um software capaz de coletar e monitorar o consumo de energia, assim como realizar o controle das cargas. O material necessário para o desenvolvimento e montagem do protótipo é imprescindível, que pode ser encontrado no mercado nacional. Além disso, o software é importante no controle via perfil de consumo traçado inicialmente. 


\section{METODOLOGIA}

Uma das metodologias utilizadas no desenvolvimento do projeto é a realização de um levantamento do consumo médio energético de acordo com o número de moradores por residência através dos relatórios gerados pela EPE (Empresa de Pesquisa Energética). Esse levantamento de consumo médio de energia pode ser classificado quanto á natureza de investigação como uma pesquisa descritiva assumindo a forma de estudo exploratória. Nesse contexto, os fatos são observados, classificados e interpretados, sem que o pesquisador interfira neles. Para o levantamento serão utilizados questionários técnicos onde os usuários residências vão informar seu consumo, quantidade de pessoas e renda mensal. Os resultados obtidos com valor médio de consumo serão comparados com a meta estabelecida pelo usuário e gerado um perfil individual. Não há nenhum risco para os usuários envolvidos na pesquisa.

O desenvolvimento das etapas do projeto deverá seguir uma ordem lógica, conforme abaixo:

- Levantamento estatístico do consumo de energia elétrica residencial;

- Desenvolvimento do circuito eletrônico;

- Desenvolvimento do software.

Inicialmente serão pesquisadas as formas de medição de tensão e corrente elétrica, o princípio de funcionamento dos possíveis sensores que serão usados nas medições e os circuitos necessários para o tratamento dos sinais, através de uma revisão bibliográfico nas áreas de elétrica e eletrônica.

Após o processo de revisão bibliográfica e pesquisas de campo, inicia-se o desenvolvimento do circuito eletrônico e software que, para facilitar e agilizar o processo será dividido em fases, conforme abaixo:

1. Módulo analógico A1: módulo responsável pelas medidas de tensão, corrente, pot6encias e fator de potência;

2. Módulo Digital D1: módulo responsável pela conversão e processamento das medidas de tensão, corrente, fator de potência e energia. Esse módulo contém o software que converte as medidas e processa, encaminhado-as para o software de monitoramento.

3. Módulo de Comunicação $C 1$ : módulo responsável pelo controle e monitoração do consumo via internet. 
4. Módulo de Acionamento de Cargas AC1: modulo responsável por controlar as cargas em função dos limites pré-estabelecidos.

As ferramentas listadas abaixo auxiliam na metodologia para elaboração dos módulos citados acima que, são elas:

- Osciloscópio Digital;

- Fonte de Alimentação;

- Gerador de funções;

- Ferro de solda;

- Medidor de indutância;

- Multímetro digital;

- Gravador de micro controlador da família PIC;

- Simulador de circuito eletrônico Proteus.

Os testes de medição deverão ser comparados por meio de instrumentos comerciais aferidos, conforme mencionados anteriormente. Após o término do protótipo, testes de funcionamento serão realizados de acordo com a seqüência indicada abaixo:

Medir o consumo diário e compará-las com os medidores convencionais;

Coletar dados das medidas e gerar relatórios e compará-los com valores aferidos pelas concessionárias de energia elétrica;

Por fim, o protótipo será submetido a testes de curto circuito e será verificada sua segurança.

\section{PESQUISA SOBRE O PERFIL ENERGÉTICO NO BRASIL}

A EPE é uma empresa pública, instituída nos termos da Lei n 10.847, de 15 de março de 2004, e do Decreto $n^{\circ} 5.184$, de 16 de agosto de 2004. Sua finalidade é prestar serviços na área de estudos e pesquisas destinados a subsidiar o planejamento do setor energético, tais como energia elétrica, petróleo e gás natural e seus derivados, carvão mineral, fontes energéticas renováveis e eficiência energética, dentre outras. O EPE juntamente com o IBGE levantou o consumo médio em kWh de energia elétrica por regiões do Brasil (IBGE, 2010). Para o Medidor Residencial Inteligente proposto, os limites serão configurados conforme os valores definidos pelo EPE e IBGE. A meta será inicialmente 
definida no medidor mediante configuração e seu valor é $60 \%$ do consumo médio definido. Valores acima do estabelecido o medidor envia alarmes sonoros informando que sua meta foi ultrapassada. Porém, existe a opção do próprio usuário definir sua meta, configurando no display de cristal liquido. As pesquisas realizadas no EPE e IBGE permitiram encontrar valores de consumo médio mensal por regiões, nesse contexto, a configuração inicial do medidor em relação aos limites de consumo será definida por esses valores. Segundo o IBGE, a estimativa da variação de preços do subitem Energia Elétrica no Sistema Nacional de Índices de Preços ao Consumidor, desde a sua implantação, é calculada a partir de uma conta teórica associada ao consumo médio mensal domiciliar de kwh obtido a partir da Pesquisa de Orçamentos Familiares e informações de preços obtidas junto às concessionárias.

Os consumos médios são específicos para cada região e população objetivo do INPC (famílias residentes nas áreas urbanas, com chefes assalariados e rendimentos mensais de 1 a 8 salários mínimos) e IPCA (famílias residentes nas áreas urbanas e rendimento mensal de 1 a 40 salários mínimos ). Nesse cenário, foi definida uma tabela com os consumos médios de energia por padrão e perfil de consumidores. A tabela 1 abaixo determina o consumo médio mensal de energia elétrica no país.

\begin{tabular}{|l|l|l|}
\hline Área & $\begin{array}{l}\text { INPC } \\
\text { Consumo Médio } \\
\text { Kwh }\end{array}$ & $\begin{array}{l}\text { INPCA } \\
\text { Consumo Médio } \\
\text { Kwh }\end{array}$ \\
\hline Brasília & 166 & 221 \\
\hline $\begin{array}{l}\text { Belo } \\
\text { Horizonte }\end{array}$ & 160 & 212 \\
\hline Recife & 109 & 151 \\
\hline São Paulo & 211 & 249 \\
\hline Belém & 181 & 222 \\
\hline Fortaleza & 104 & 143 \\
\hline Rio de & 116 & 210 \\
\hline
\end{tabular}




\begin{tabular}{|l|l|l|}
\hline Janeiro & & \\
\hline Goiânia & 174 & 220 \\
\hline Salvador & 131 & 171 \\
\hline Curitiba & 137 & 196 \\
\hline
\end{tabular}

Tabela 1: Consumo mensal médio de Energia Elétrica

(IBGE, 2010)

Os valores definidos inicialmente em relação às metas para geração de alarmes e desligamentos automáticos de cargas baseiam-se inicialmente nos dados estatísticos estabelecidos pelo IBGE em conjunto com o IPE.

Outro ponto pesquisado foi em relação ao chuveiro elétrico, que é uma carga presente em boa parte das residências em nosso país. Em 1983 foi realizada uma pesquisa intitulada "Consumos residenciais de energia", para o Conselho Estadual de Energia de São Paulo, realizada na área de atuação da Eletropaulo. O chuveiro elétrico foi um dos aparelhos pesquisados. A pesquisa ocorreu nos meses de setembro a outubro, sendo realizada em 133 residências de funcionários da empresa, em duas etapas. A primeira etapa constituiu-se em aplicação de questionário sócio-econômico e a segunda de medições. Esta última é a de interesse deste estudo, e neste tópico, particularmente o tempo de banho. Os dados dessa pesquisa são utilizados até hoje pelo sistema elétrico brasileiro (Comissão de Serviços Públicos de Energia, 2001).

Nessa pesquisa o tempo médio de duração de um banho é de 8 minutos, valor que vamos adotar para que essa carga possa ser desligada quando o tempo for ultrapassado. Nesse contexto, o Medidor Residencial Inteligente é préconfigurado conforme os dados pesquisados e informados nesse projeto. 


\section{DESENOLVIMENTO DO PROJETO}

\section{a. Família de Microcontroladores PIC utilizado no projeto}

O microcontrolador é um circuito integrado programável que contém todos os componentes de um computador como CPU (unidade central de processamento), memória para armazenar programas, memória de trabalho, portas de entrada e saídas para comunicar-se com o mundo exterior, sistema de controle de tempo interno e externo, conversor analógico para digital, UART de comunicação e outros. Pode-se controlar qualquer coisa ou estar incluído em unidades de controle para:

- máquinas pneumáticas, hidráulicas comandadas

- máquinas dispensadoras de produtos

- motores, temporizadores

- sistemas autônomos de controle, incêndio, umidade temperatura

- telefonia, automóveis, medicina etc.

Estamos rodeados por máquinas que realizam algum trabalho ajudado por sensores e atuadores que recolhem as informações. Uma das razões do sucesso do PIC é à base de sua utilização, ou seja, quando se aprende a trabalhar com um modelo, fica fácil migrar para outros modelos já que todos têm uma estrutura parecida (SILVA, 2006).

\section{b. $\quad$ Características do PIC 18F4620}

O Microcontrolador escolhido para uso neste trabalho de pesquisa é o PIC 18F4620, devido ao fato de ser facilmente encontrado no mercado nacional e por possuir o conjunto de memória, periféricos e capacidade de processamento requerido nas especificações do projeto de pesquisa aliado a um custo baixo.

As características a seguir foram retiradas do datasheet do PIC 18F4620 fabricado pela Microchip:

$\rightarrow$ Microprocessador de 8 bits com capacidade de 10MIPS;

$\rightarrow$ 64kbytes de memória FLASH;

$\rightarrow 36$ pinos de I/O distribuídos em 5 PORT's bidirecionais; 
$\rightarrow$ Clock externo de até $40 \mathrm{MHz}$ e $8 \mathrm{MHz}$ interno;

$\rightarrow 4$ Timers;

$\rightarrow$ Interrupções com dois níveis de prioridade;

$\rightarrow$ Canais de PWM;

$\rightarrow$ Portas de comunicação UART, I2C, SPI;

$\rightarrow 13$ entradas analógicas de 10bits.

A figura 1 mostra os pinos do PIC 18F4620 em encapsulamento plástico PDIP de 40 pinos e a figura 2 mostra a arquitetura HARVARD típica através do diagrama de blocos internos do microcontrolador, com todos os barramentos, memórias, ALU, blocos do sistema de controle, portas e periféricos.

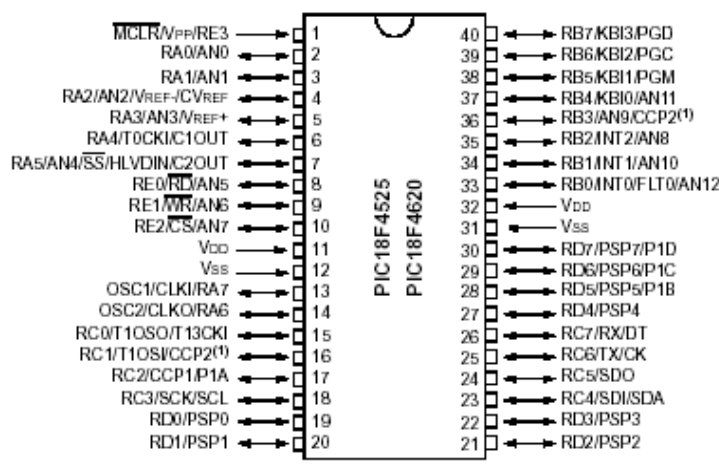

Figura 1 - Diagrama da PIC18F4620 em encapsulamento plástico de 40 pinos. Fonte: (Adaptado de MICROCHIP, 2010). 


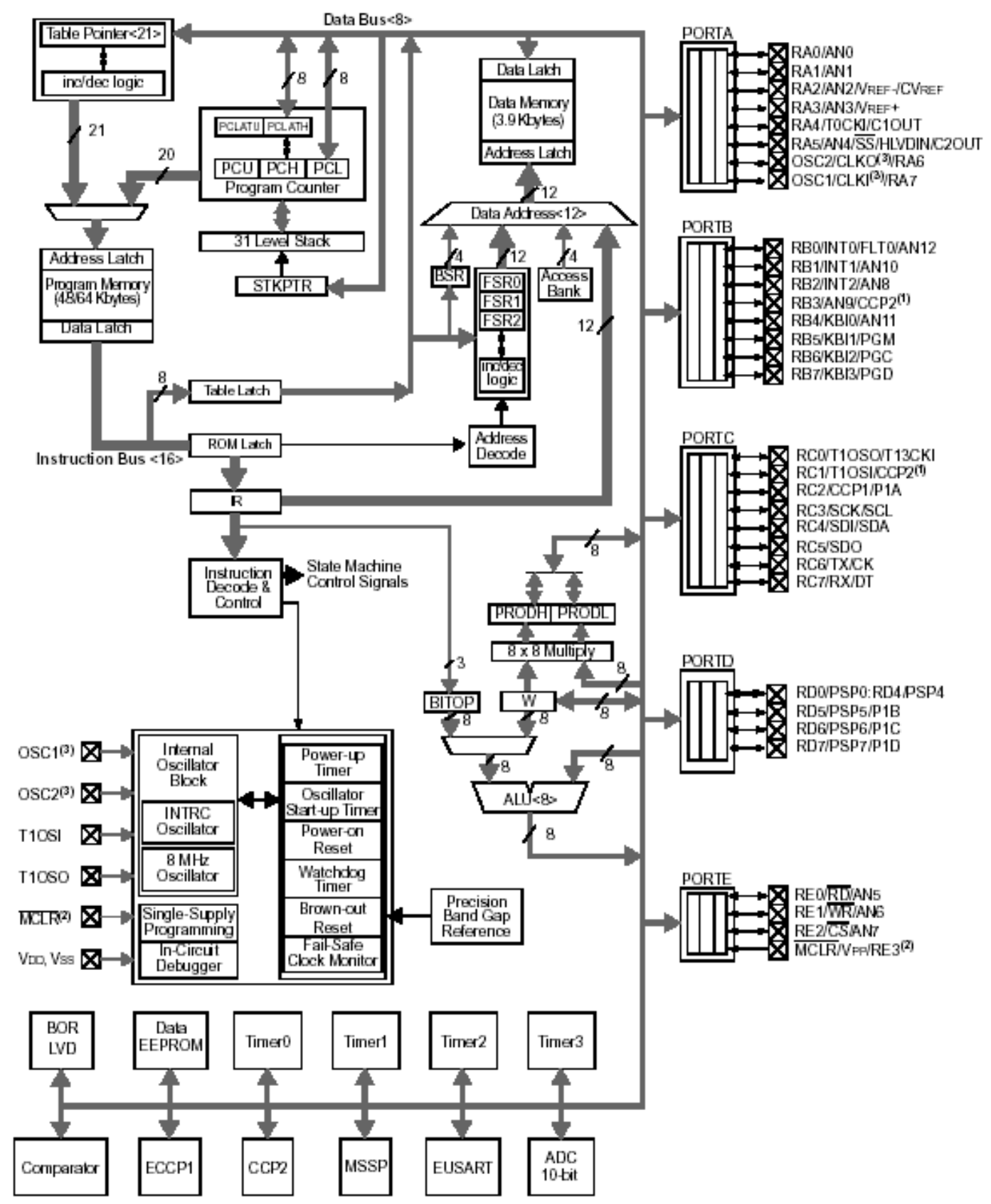

Figura 2 - Diagrama de blocos do microcontrolador.

Fonte: (Adaptado de MICROCHIP, 2010).

c. Arquitetura Interna do PIC

Entende-se por arquitetura interna a forma como o circuito é construído, representada por blocos, isto é como suas partes internas se interligam, podemos definir os PICs como sendo "Arquitetura Harvard", onde a CPU é interligada à memória de dados (RAM) e a memória de programa (EPROM) por um barramento específico. Tradicionalmente os microprocessadores têm como 
base a estrutura de Von Neumann, que se caracteriza por dispor de uma única memória principal em que se armazenam dados e instruções. $O$ acesso à memória é feito através de um sistema de uma única via (bus de dados, instruções e de controle).

A arquitetura interna do PIC é do modelo Harvard, onde dispõe de memórias de dados e de programas. Cada memória dispõe de seu respectivo bus, o que permite, que a CPU possa acessar de forma independente a memória de dados e a de instruções. Como as vias (bus) são independentes estes podem ter conteúdos distintos na mesma direção. A separação da memória de dados da memória de programa faz com que as instruções possam ser representadas por palavras de mais que 8 bits, assim o PIC, usa 14 bits para cada instrução, o que permite que todas as instruções ocupem uma só palavra de instrução, sua arquitetura ortogonal, onde qualquer instrução pode utilizar qualquer elemento da arquitetura como fonte ou destino. Todo o processo baseia-se em banco de registros onde todos os elementos do sistema como, temporizadores, portas de entrada / saída, posições de memórias que, estão implementados fisicamente como registros.

\section{d. $\quad$ C Ciclo de Máquina}

O oscilador externo (geralmente um cristal) ou o interno (circuito $\mathrm{RC}$ ) é usado para fornecer um sinal de clock ao microcontrolador. O clock é necessário para que o microcontrolador possa executar as instruções de um programa.

Nos microcontroladores PIC, um ciclo de máquina (CM) possui quatro fases de clock que são Q1, Q2, Q3 e Q4. Dessa forma, para um clock externo de $4 \mathrm{MHz}$, temos um ciclo de máquina $(\mathrm{CM}=4 \times 1 / \mathrm{F})$ igual a $1 \mu \mathrm{s}$. O Contador de Programa (PC) é incrementado automaticamente na fase $Q 1$ do ciclo de máquina e a instrução seguinte é resgatada da memória de programa e armazenada no registro de instruções da CPU no ciclo Q4. Ela é decodificada e executada no próximo ciclo, no intervalo de Q1 e Q4. Essa característica de buscar a informação em um ciclo de máquina e executá-la no próximo, ao mesmo tempo em que outra instrução é "buscada", é chamada de PIPELINE (sobreposição). Ela permite que quase todas as instruções sejam executadas em apenas um 
ciclo de máquina, gastando assim $1 \mu$ s (para um clock de $4 \mathrm{MHz}$ ) e tornando o sistema muito mais rápido. As únicas exceções referem-se às instruções que geram "saltos" no contador de programa, como chamadas de funções em outro local da memória de programa e os retornos dessas funções (SOUZA,2007).

A figura 3 ilustra o funcionamento do ciclo de máquina para um microcontrolador típico da família PIC. As vantagens da arquitetura de Harvard sobre a de Von Newman ficam evidentes se compararmos um PIC rodando com freqüência de clock de $4 \mathrm{MHz}$ e um 8051 com clock de 12MHz. Ambos os controladores estarão operando com ciclo de máquina de $1 \mu \mathrm{s}$, ou seja, teoricamente serão capazes de realizar 1 milhão de operações por segundo (1MIPS). Na prática essa taxa não é atingida, pois no caso do PIC a maioria de suas instruções são realizadas em um ciclo de máquina, exceção das instruções de salto que consomem 2 ciclos de máquina. A taxa para o 8051 é pior, porque este microcontrolador tem instruções que necessitam de 1 a 11 ciclos de máquina para serem executadas.

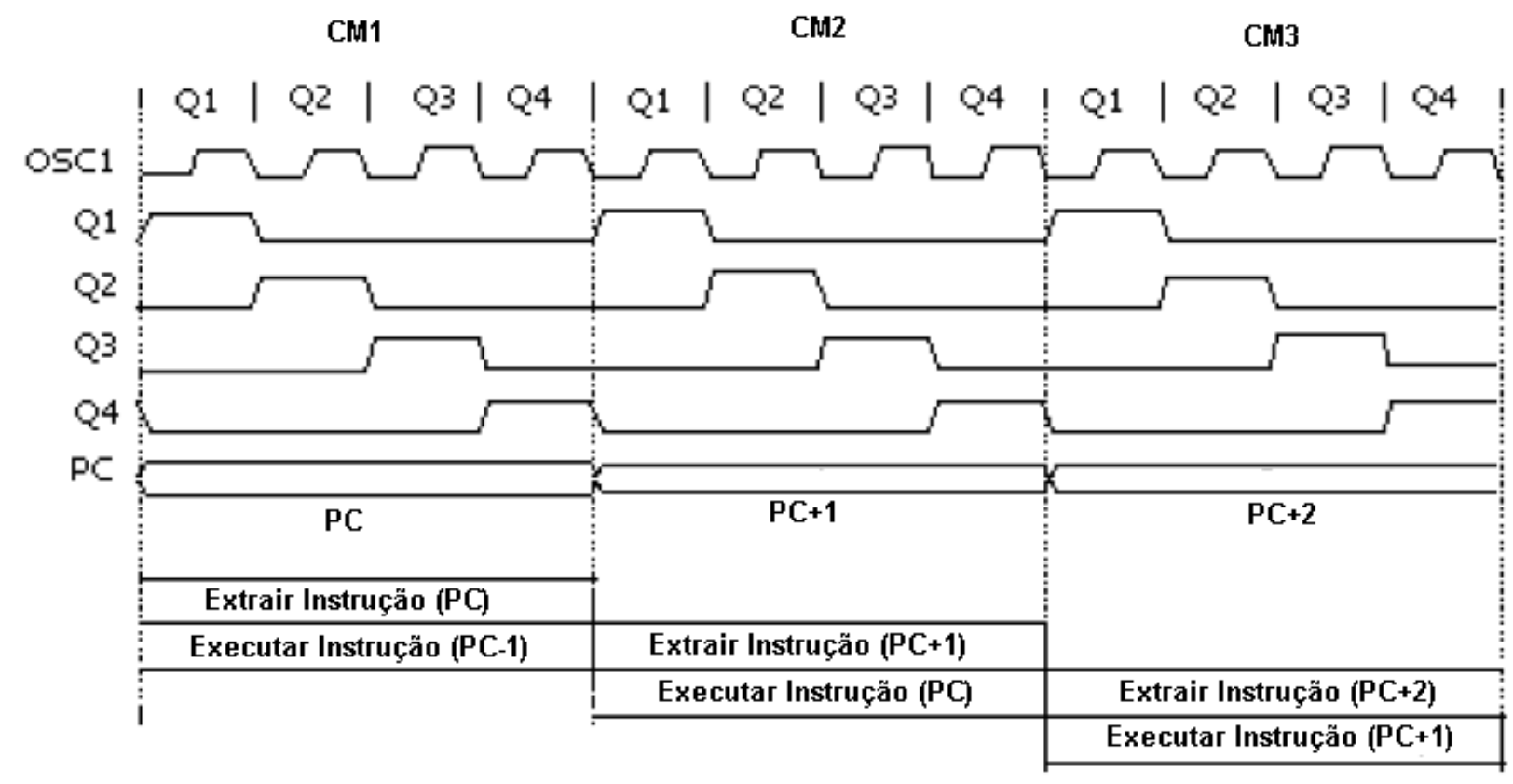

Figura 3 - Diagrama do ciclo máquina de um PIC.

Fonte: (Adaptado de SOUZA, 2007). 


\section{e. Interrupções}

As interrupções são causadas através de eventos assíncronos (podem ocorrer a qualquer momento) causando um desvio no processamento. Este desvio tem como destino um endereço para tratamento da interrupção. Uma boa analogia para melhor entendermos o conceito de interrupção é a seguinte: você está trabalhando digitando uma carta no computador quando o seu telefone toca. Neste momento você, interrompe o que está fazendo, para atender ao telefone e verificar o que a pessoa do outro lado da linha está precisando. Terminada a conversa, você coloca o telefone no gancho novamente e retoma o seu trabalho do ponto onde havia parado. Observe que não precisamos verificar a todo instante, se existe ou não alguém na linha, pois somente quando o ramal é chamado, o telefone toca avisando que existe alguém querendo falar com você. Após do atendimento das interrupções, o microcontrolador retorna exatamente ao ponto onde parou no programa antes de atendê-la. As interrupções mais comuns na família PIC18F são:

- pela interrupção externa 0 (Pino B0) -> enable_interrupts(int_ext);

- pela interrupção externa 1 (Pino B1) -> enable_interrupts(int_ext1);

- pela interrupção externa 2 (Pino B2) -> enable_interrupts(int_ext2);

- pelo contador/temporizador 0 -> enable_interrupts(int_timer0);

\section{f. Memórias}

Um microcontrolador possui diversas memórias, cada uma apresenta uma funcionalidade, podemos destacar:

Memória de Programa - é o local onde é gravado o código hexadecimal do programa que o microcontrolador irá executar. Existem basicamente dois tipos de memórias usadas, os chips que possuem a letra "F" em seu nome código possuem uma memória do tipo $\mathrm{FLASH}$, o que permite inúmeras regravações e facilitando muito o desenvolvimento de protótipos, dispositivos que devam prever atualizações do firmware e para fins de aprendizagem. Os chips com código "C" são possuem memórias EEPROM que permitem uma única gravação, sendo empregados em equipamentos já testados e em fase de produção em escala, são mais baratos que os modelos que possuem memórias do tipo FLASH. 
Memória de Instruções - é um tipo de BIOS (binary input and output system), servindo para que CPU saiba o que fazer com o código hexadecimal lido do programa gravado na memória de programa.

Memória EEPROM interna - é uma memória do tipo EEPROM presente na maioria dos microcontroladores PIC e pode ser usada para guardar valores de inicialização, preferências, e medidas de sensores, de forma que não sejam perdidos durante o desligamento ou inicialização do sistema.

Memória de dados RAM - é onde ficam armazenados os valores dos registradores de funções especiais e as variáveis definidas pelo programa em execução, os valores são perdidos durante o desligamento e ou a inicialização do sistema, por essa razão a RAM também é conhecida por memória volátil.

\section{g. Principais Registradores de Controle}

Para programar os microcontroladores é importante conhecer os registros especiais e saber configurar todas as funções dos periféricos internos. A seguir temos os principais registradores encontrados nos microcontroladores PIC. As figuras 4 a 13 mostram as configurações dos bits dos principais registradores presentes nos PIC das famílias 16 e 18.

Registrador STATUS: Serve para selecionar o qual banco de memória será usado, se a máquina está em modo SLEEP, se ocorreu um RESET por WatchDog e se a operação efetuada resultou em zero ou houve estouro na ULA.

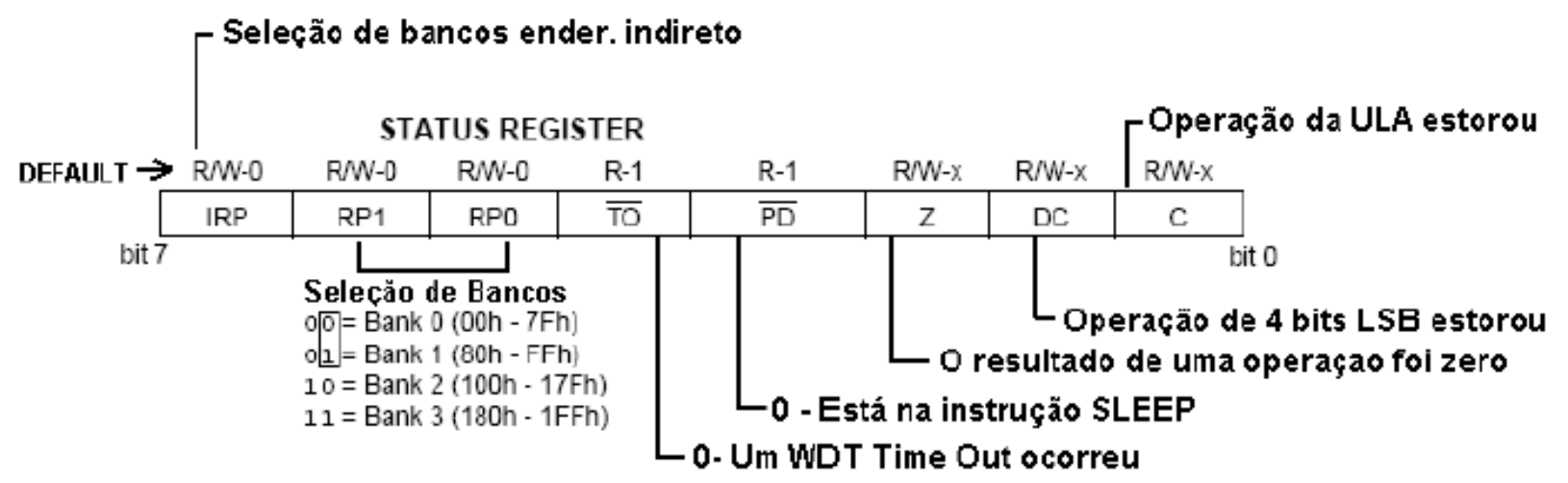

Figura 4 - Diagrama do registrador de STATUS.

Fonte: (Adaptado de MICROCHIP, 2010).

Registrador INTCOM: 
Gerenciamento das interrupções do microcontrolador e sinalização do estouro do Timer 0.

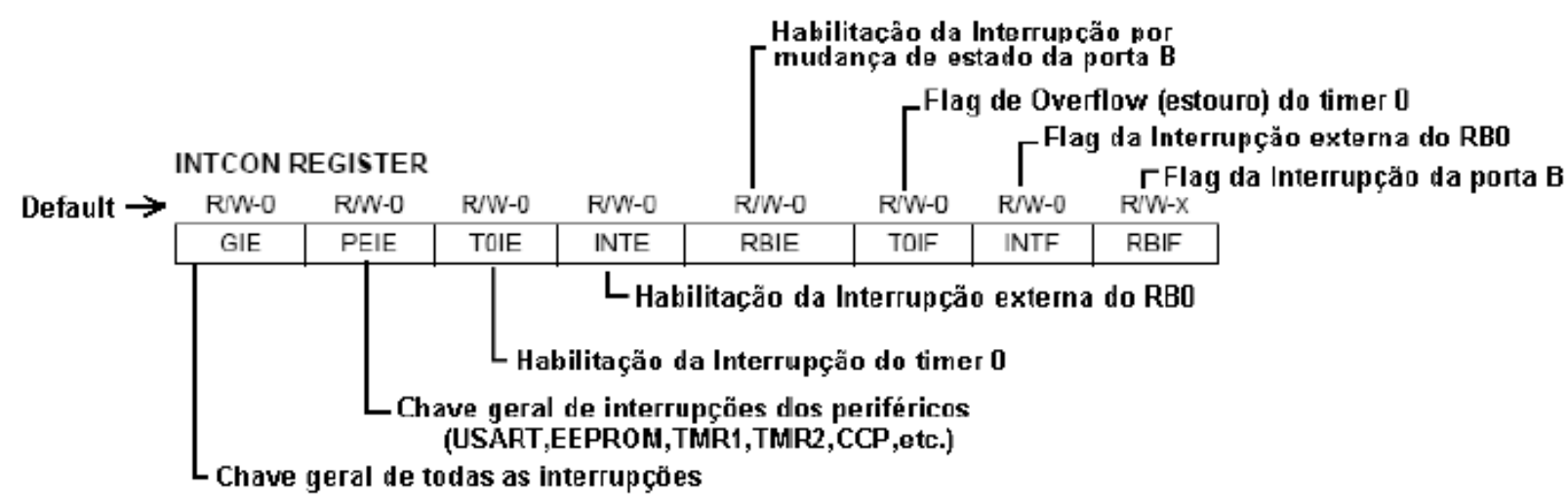

Figura 5 - Diagrama do registrador INTCON.

Fonte: (Adaptado de MICROCHIP, 2010).

Registrador PIE1:

Habilita as interrupções dos periféricos presentes no microcontrolador.

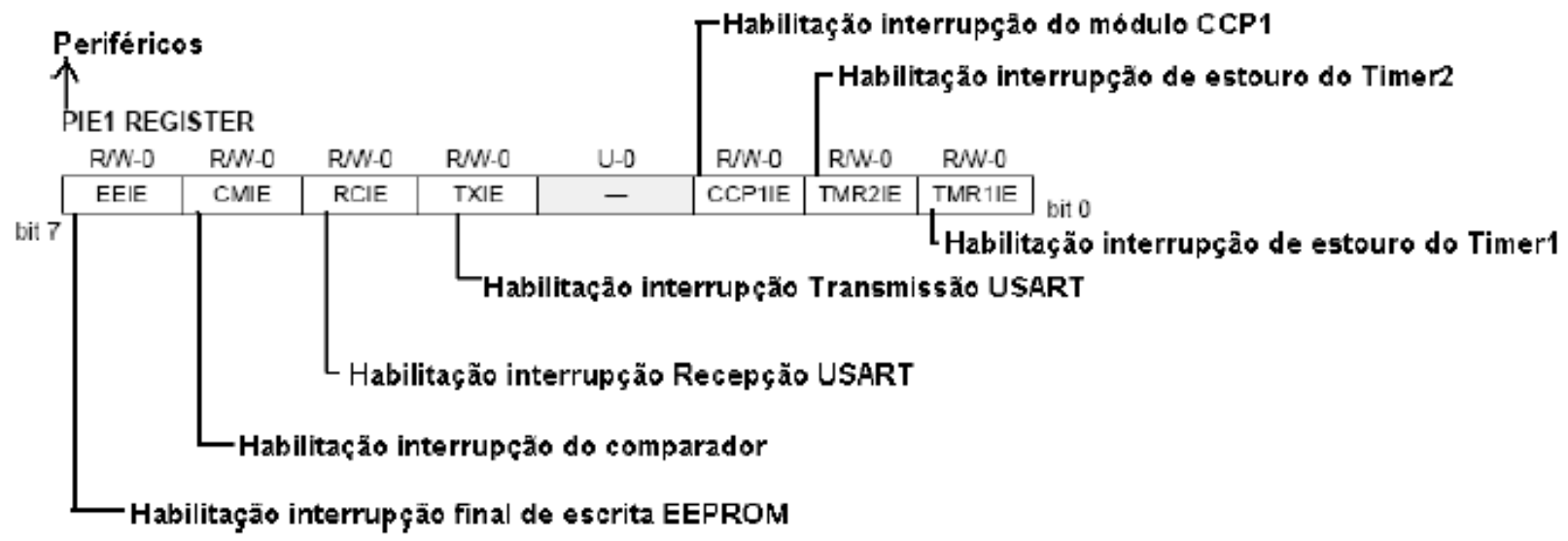

Figura 6 - Diagrama do registrador PIE1.

Fonte: (Adaptado de MICROCHIP, 2010).

Registrador PIR1:

Sinaliza a ocorrência de interrupções nos periféricos habilitados. 


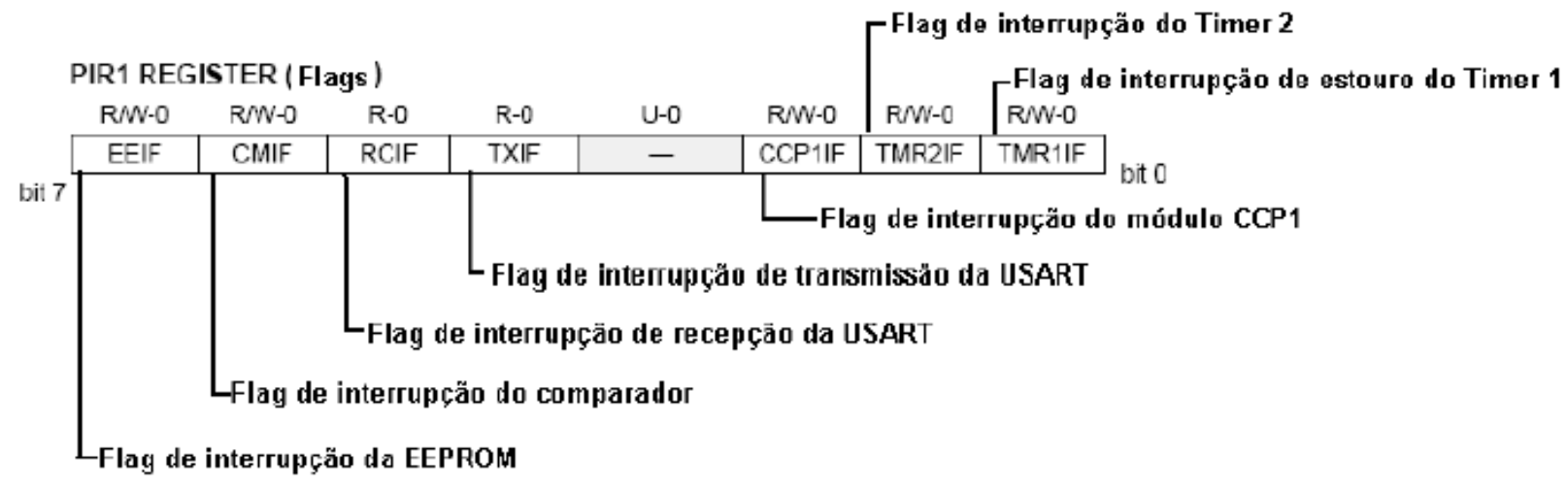

Figura 7 - Diagrama do registrador PIR1.

Fonte: (Adaptado de MICROCHIP, 2010).

Registrador OPTION_REG:

Este registrador serve basicamente para configurar o TIMER0, o WDT, seleção da borda da interrupção externa e dos resistores de PULL UP do PORTB.

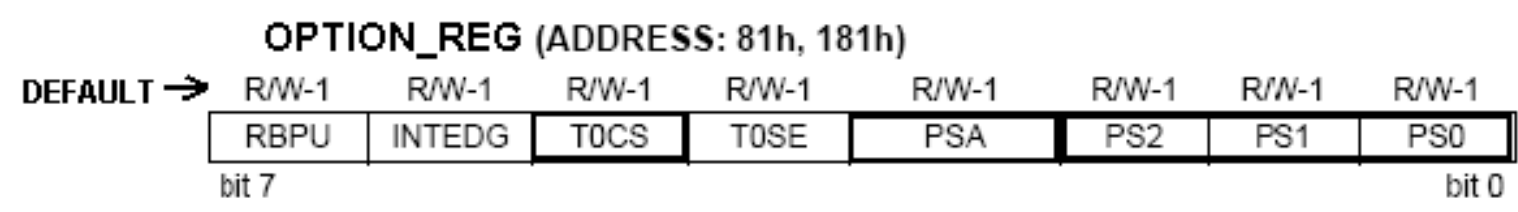

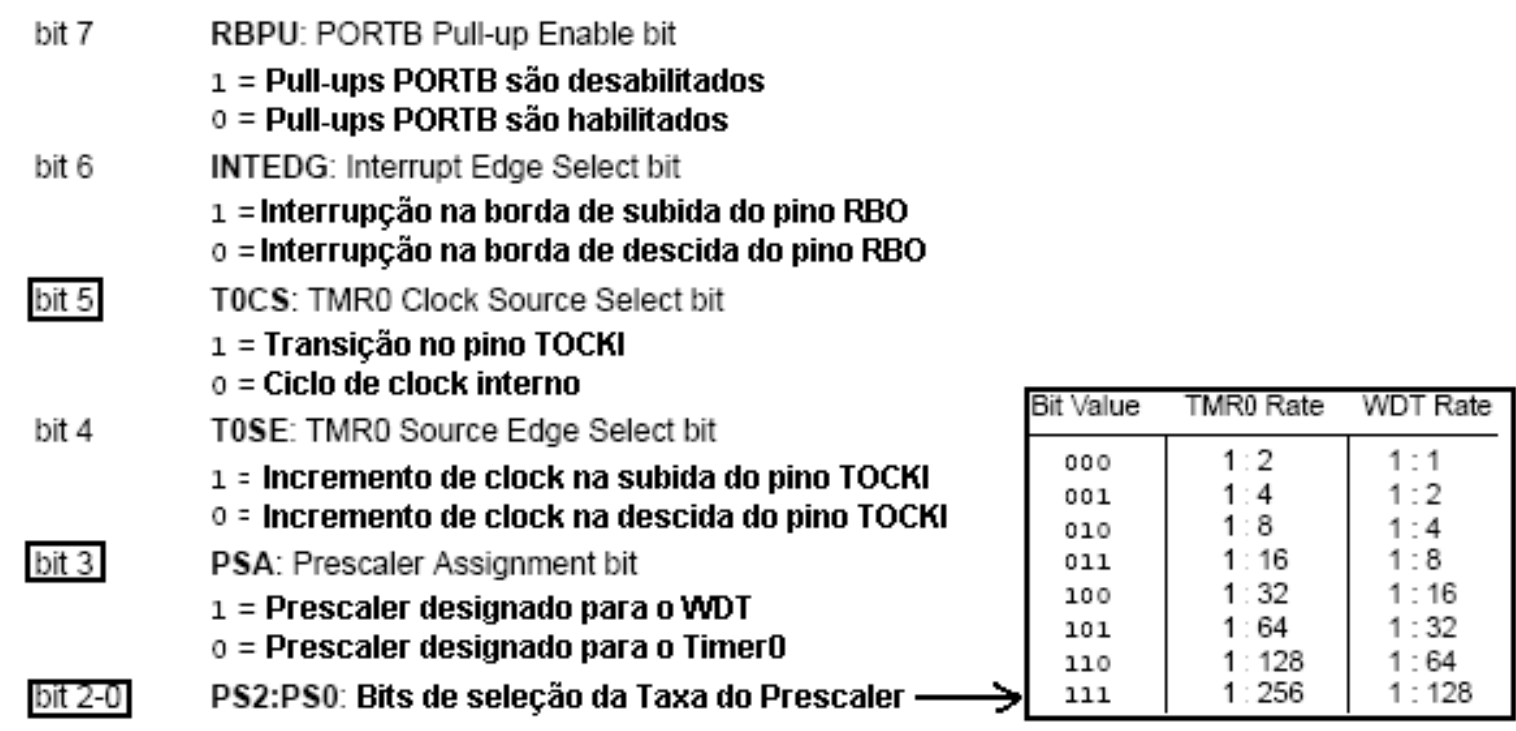

Figura 8 - Diagrama do registrador OPTION_REG.

Fonte: (Adaptado de MICROCHIP, 2010).

Registrador T1CON:

Configura o funcionamento do TIMER1. 


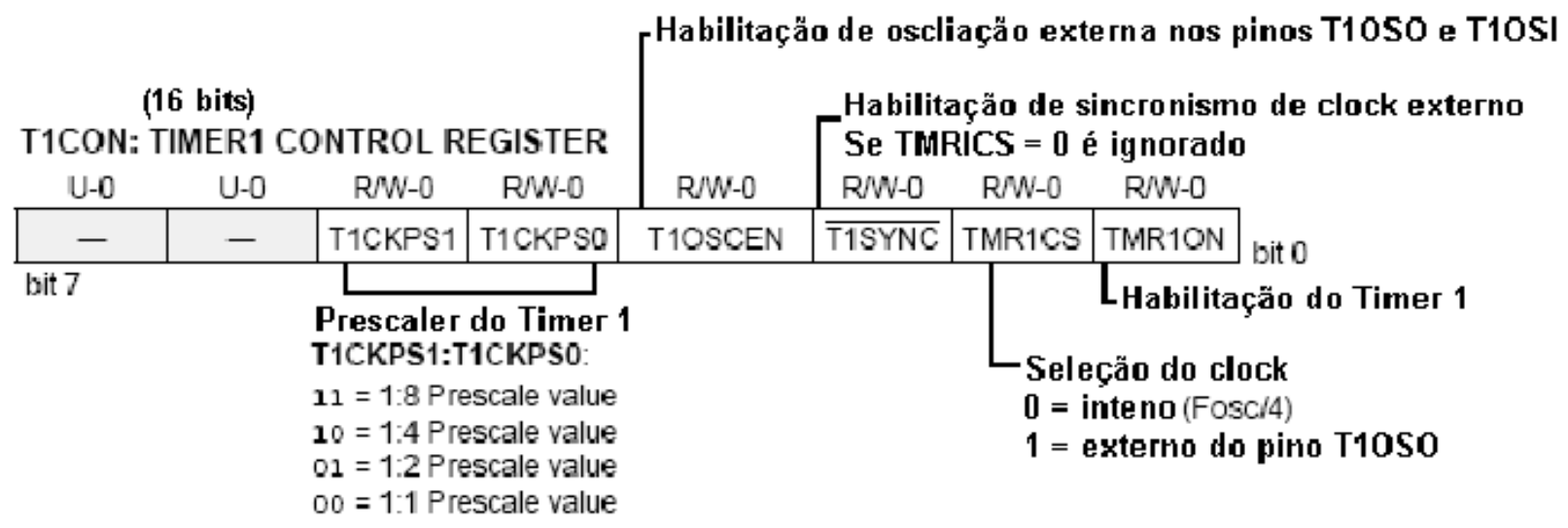

Figura 9 - Diagrama do registrador TIMER1.

Fonte: (Adaptado de MICROCHIP, 2010).

Registrador PCON:

Sinaliza a ocorrência de reset por baixa tensão e por inicialização e seleciona a freqüência do oscilador interno quando este for usado.

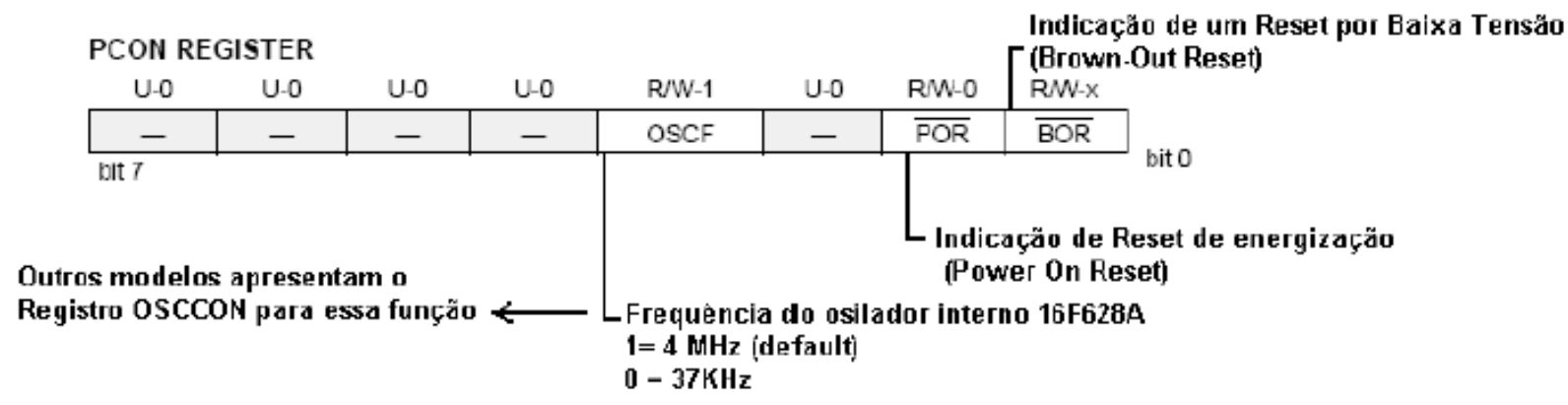

Figura 10 - Diagrama do registrador PCON.

Fonte: (Adaptado de MICROCHIP, 2010).

Registrador OSCON:

Controle das opções do oscilador de clock do microcontrolador. 


\section{OSCCON - OSCILLATOR CONTROL REGISTER (ADDRESS: 8Fh) PIC16F688}

\begin{tabular}{|c|c|c|c|c|}
\hline & $\mathrm{U}-0$ & $\mathrm{R} N-1$ & $\mathrm{R} / \mathrm{N}-1$ & $\mathrm{R} / \mathrm{-O}$ \\
\hline & - & IRCF2 & IRCF1 & IRCFO \\
\hline \multirow{9}{*}{ bit 7} & \multicolumn{4}{|c|}{ Bit de selecăo do oscilador interno } \\
\hline & \multicolumn{2}{|c|}{$000=$} & \multicolumn{2}{|c|}{$31 \mathrm{kHz}$} \\
\hline & & $001=$ & \multicolumn{2}{|c|}{$125 \mathrm{kHz}$} \\
\hline & & $010=$ & \multicolumn{2}{|c|}{$250 \mathrm{kHz}$} \\
\hline & & $011=$ & \multicolumn{2}{|c|}{$500 \mathrm{kHz}$} \\
\hline & & $100=$ & \multicolumn{2}{|c|}{$1 \mathrm{MHz}$} \\
\hline & & $101=$ & \multirow{2}{*}{\multicolumn{2}{|c|}{$2 \mathrm{MHz}$}} \\
\hline & & $110=$ & & $4 \mathrm{MHz}$ \\
\hline & & $111=$ & \multicolumn{2}{|l|}{$8 \mathrm{MHz}$} \\
\hline
\end{tabular}

OSTS: Oscillator Start-up Time-out Status bit

$1=$ Device is running from the external system clock defined by $F O S C<2: 0\rangle$

$0=$ Device is running from the internal system clock (HFINTOSC or LFINTOSC)

Figura 11- Diagrama do registrador OSCON.

Fonte: (Adaptado de MICROCHIP, 2010).

Registrador PORTA, B, C, D, E:

Esses registros indicam o valor das portas de entrada e saída do microcontrolador. Em relação aopull-up interno (conexão ao VDD para que o pino possa utilizar o nível lógico alto na saída), aconfiguração é variável para cada modelo, para o PIC16F4620 o Port A (com pull-up de 0 a 3, os demais Tristate), Port B (pull-up interno configurável por software), Port C (com pull-up) e PORT D e E (Tristate).

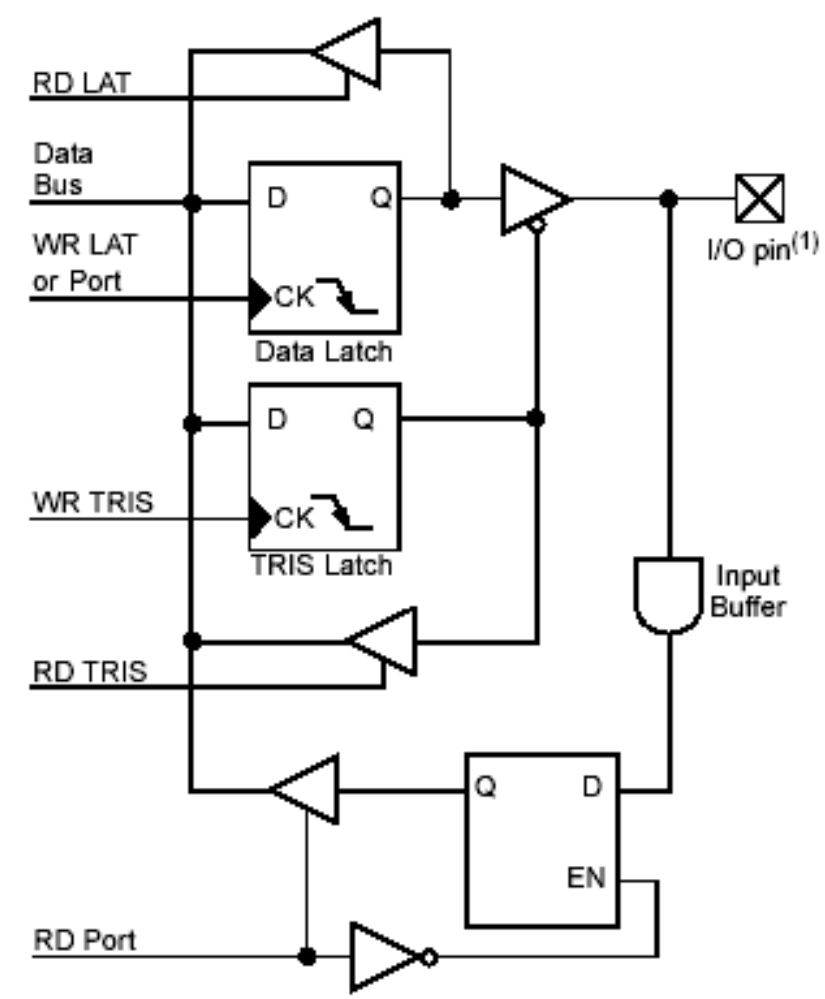

Note 1: I/O pins have diode protection to VDD and VSS 
Figura 12- Diagrama de blocos de um pino de I/O genérico.

Fonte: (Adaptado de MICROCHIP, 2010).

Registrador TRIS:

Esses registradores servem para configurar os pinos das portas como entrada ou saída. Quando é colocado "1" em um bit do TRIS, o pino relacionado a ele é configurado como entrada. Para configurar um pino como saída, é necessário escrever "0" no bit relacionado. Uma maneira prática para memorizar essa regra é associar "1" ao "l" de Input (entrada) e o "0" ao "O" de Output (saída). Para configurar o PORTA, deve ser utilizado o registrador TRISA, para o PORTB é utilizado o TRISB, etc.

Registrador TXSTA e RCSTA:

São usados para controle da porta de comunicação serial síncrona e assíncrona.

\section{TXSTA: REGISTRO DE CONTROLE E STATUS DA TRANSMISSAO}

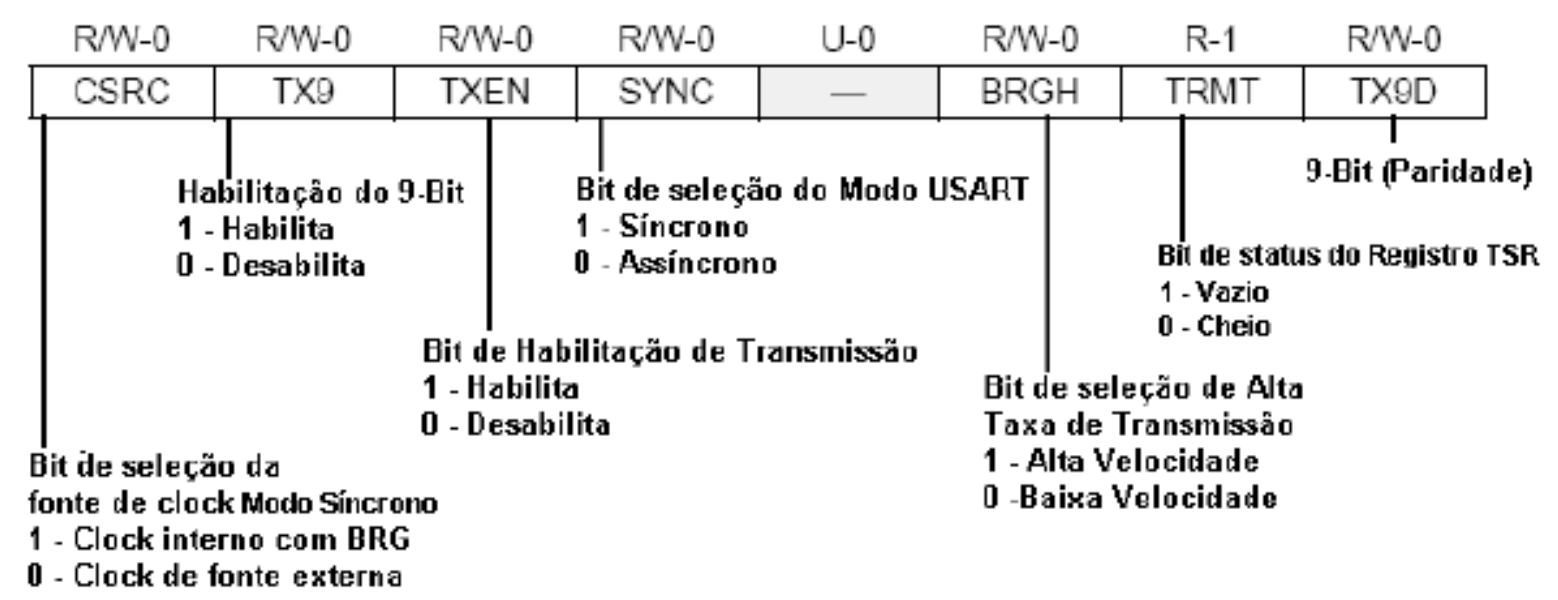


RCSTA: REGISTRO DE CONTROLE E STATUS DARECEPÇÃO

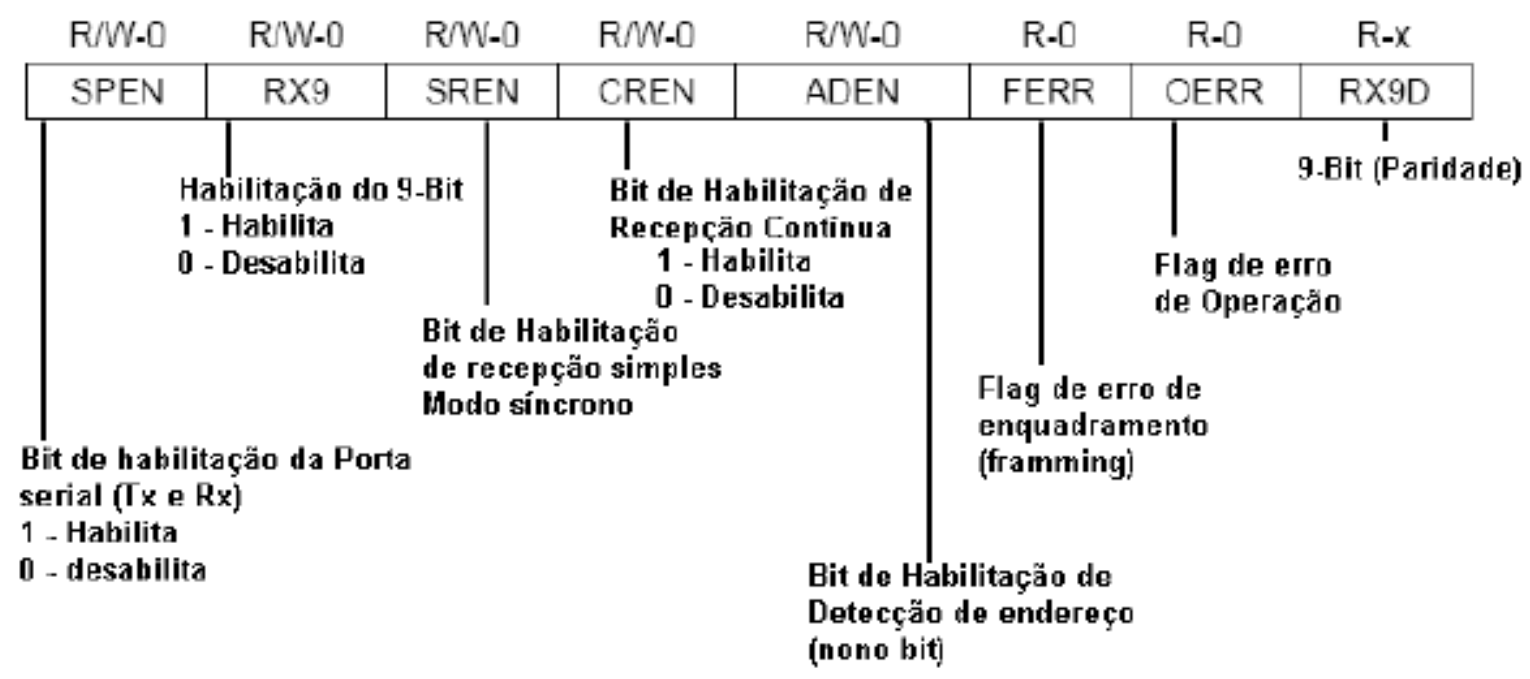

Figura 13 - Diagrama do registradores TXSTA e RCSTA.

Fonte: (Adaptado de MICROCHIP, 2010).

\section{h. Conversor Analógico Digital}

O objetivo do conversor analógico-digital $(A D)$ é converter um sinal analógico, geralmente de 0 a $5 \mathrm{~V}$, em equivalentes digitais. Como pode ser visto, algumas configurações permitem ainda que os pinos A3 e A2 sejam usados como referência externa positiva e negativa, fazendo com que uma leitura seja feita em uma faixa de tensão mais restrita como, por exemplo, de 1 a 3 Volts. É comum se utilizar o conversor AD com sensores de temperatura (como o LM35), luminosidade (como LDRs), pressão (STRAIN-GAGE), tensão, corrente, umidade, etc. A figura 14 mostra o diagrama de blocos do conversor A/D. 


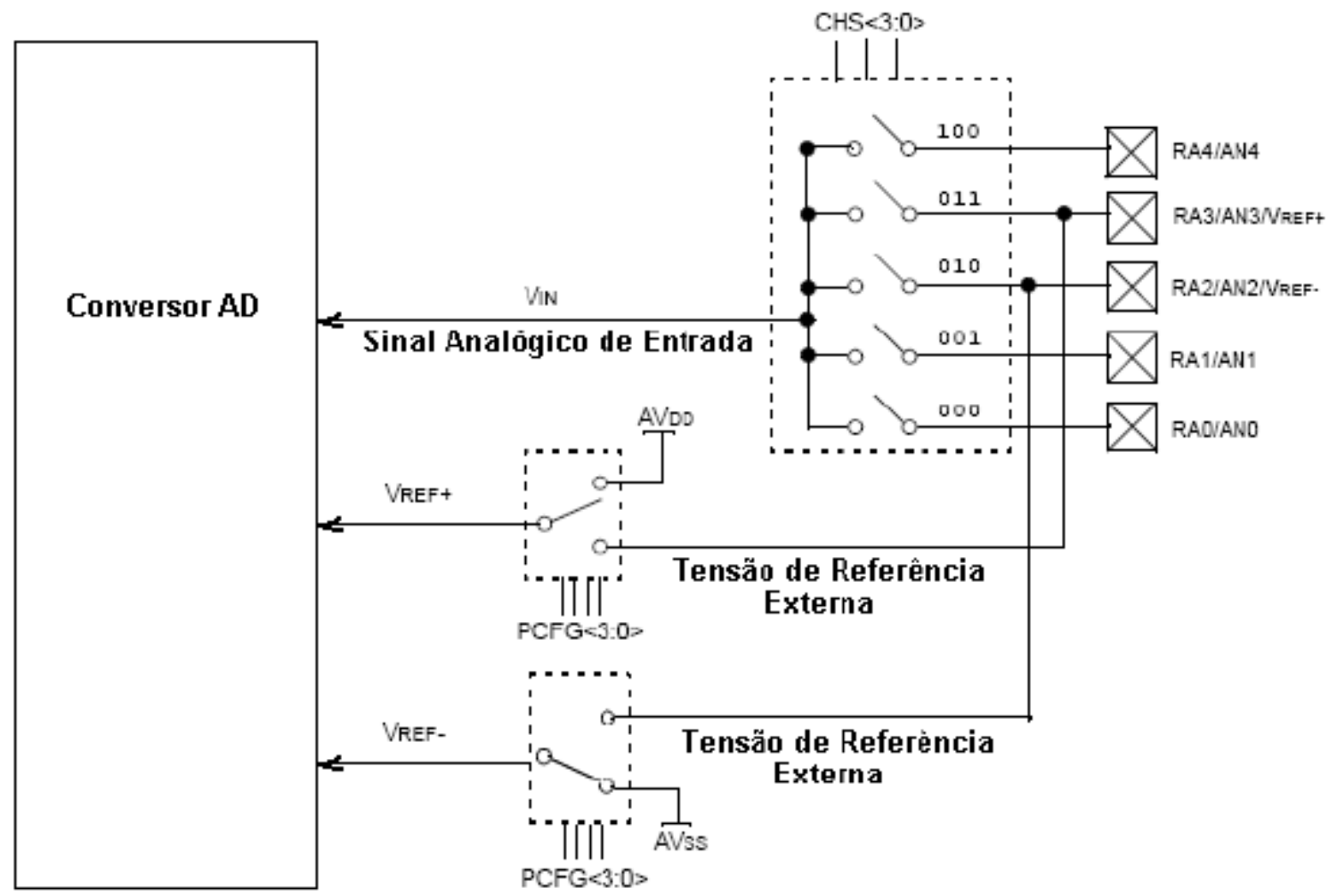

Figura 14 - Diagrama de blocos do módulo de conversão A/D.

Fonte: (Adaptado de MICROCHIP, 2010).

i.

\section{O Amplificador operacional utilizado}

Um amplificador operacional (Amp Op) é um amplificador de tensão, com alto ganho, alta impedância de entrada, baixa impedância de saída e banda larga. $O$ sinal na saída é resultado da diferença entre suas entradas chamadas de não inversora (+) e inversora (-) em relação à massa. $O$ amplificador operacional é normalmente alimentado por uma fonte simétrica, mas dependendo da aplicação uma fonte simples pode ser suficiente.

Com a finalidade de reduzirmos a sensibilidade de um sistema de controle aos distúrbios externos e para melhorar os parâmetros reais usa-se a realimentação, que consiste em desviar uma pequena porção do sinal de saída para a entrada desse sistema, contribuindo para melhor controlar o sinal de saída. O amplificador operacional pode ser utilizado sem realimentação, com realimentação negativa ou com realimentação positiva. A realimentação positiva normalmente é usada em circuitos osciladores, em aplicações de comparadores sem histerese não é usado realimentação, a realimentação negativa é usada na 
maioria dos circuitos para controlar o ganho do amplificador operacional (LANDO, 1983).

7.9.1 Circuitos básicos

Todos os circuitos que utilizam Amp Op derivam de dois circuitos básicos: o amplificador inversor e o amplificador não inversor.

Vamos definir o conceito de terra virtual, na maioria dos circuitos com Amp Op a entrada não inversora é ligada diretamente ao terra, potencial zero. Como o ganho de um Amp Op é muito elevado, basta uma diferença infinitesimal entre as duas entradas para o funcionamento do dispositivo. Desta forma, o potencial da entrada inversora é praticamente o mesmo do terra, e podemos assumir que a entrada é um terra virtual.

\section{Amplificador inversor}

Na figura 15 temos o circuito do amplificador inversor, considerando a entrada não inversora como terra virtual, portanto zero Volts, as correntes de entrada e saída podem ser representadas pelas equações 1 e 2 .

$$
\text { Ie }=\frac{\text { Vinp }}{R 1}
$$

$$
I s=\frac{\text { Vout }}{R 2}
$$

(2)

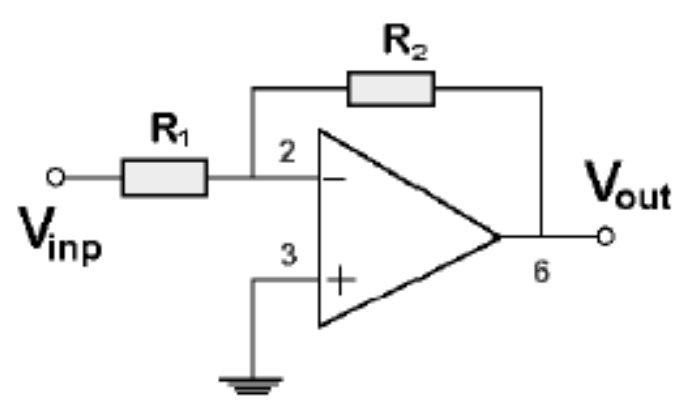

Figura 15 - Diagrama do amplificador inversor. 
Fonte: (Lando, 1983).

Desta forma podemos dizer que a tensão de saida será igual a equação 3:

Vout $=\frac{-R 2}{R 1} \cdot \operatorname{Vinp}$

O sinal negativo simboliza o rebatimento de $180^{\circ}$ na fase do sinal de saida em relação ao de entrada.

\subsubsection{Amplificador não inversor}

Para análise do amplificador não inversor, devemos sempre considerar que as tensões ente as entradas inversora e não inversora são praticamente iguais, portanto para o circuito da figura 16 temos que Vin está quase totalmente sobre R1 e determinar a tensão de saída Vout usando as equações 4 e 5.

$$
\operatorname{Vin}=\frac{\operatorname{Vin}}{R 1}
$$

Vout $=\operatorname{Vin} *\left(1+\frac{R 2}{R 1}\right)$

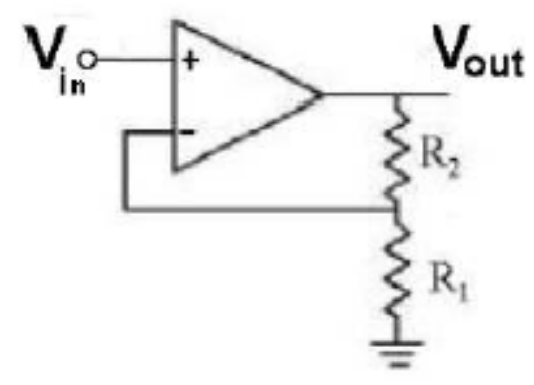

Figura 16 - Diagrama do amplificador não inversor.

Fonte: (Lando, 1983).

Portanto no amplificador não inversor o sinal de saida recebe o ganho de $1+\mathrm{R} 1 / \mathrm{R} 2$ e o tem a mesma fase da entrada. 


\section{O DISPLAY DE CRISTAL LÍQUIDO}

O LCD, ou display de cristal líquido, é um dos periféricos mais utilizados como dispositivo de saída em sistemas eletrônicos. Ele contém um microprocessador de controle, uma RAM interna que mantém escritos no display (DDRAM) os dados enviados pelo microcontrolador e uma RAM de construção de caracteres especiais (CGRAM). A figura 17 mostra um display 16x2 comum.

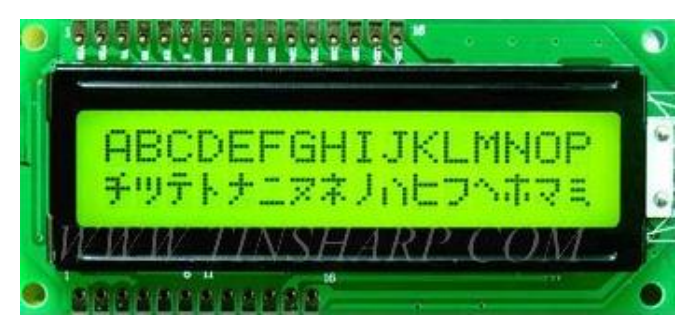

Figura 17 - Foto de um LCD básico.

Os displays mais comuns apresentam 16 colunas e duas linhas. Eles têm normalmente 14 pinos ou 16 pinos. Destes, oito pinos são destinados para dados ou instrução, seis são para controle e alimentação do periférico e dois para backlight. O LED backlight iluminação de fundo) serve para facilitar as leituras durante a noite.

Normalmente, o microcontrolador apenas envia dados e comandos para o display portanto o pino R/W pode ficar aterrado. O pino RS tem a função de informar se os dados no barramento D0 a D7 correspondem a comandos (RS=0) ou caracteres $(R S=1)$. $O$ pino $E$ tem como função determinar quando o display deve ler o barramento. A figura 17 mostra as principais instruções para comunicação com o LCD. 


\begin{tabular}{|c|c|c|c|c|}
\hline DESCRIÇÃO & MODO & RS & $\mathbf{R} / \mathbf{W}$ & $\begin{array}{c}\text { Código } \\
\text { (Hex) }\end{array}$ \\
\hline \multirow[t]{2}{*}{ Display } & Liga (sem cursor) & 0 & 0 & $\mathbf{0 C}$ \\
\hline & Desliga & 0 & 0 & $0 \mathrm{~A} / 08$ \\
\hline Limpa Display com Home cursor & & 0 & 0 & 01 \\
\hline \multirow[t]{7}{*}{ Controle do Cursor } & Liga & 0 & 0 & $0 \mathbf{E}$ \\
\hline & Desliga & 0 & 0 & $0 \mathrm{C}$ \\
\hline & Desloca para Esquerda & 0 & 0 & 10 \\
\hline & Desloca para Direita & 0 & 0 & 14 \\
\hline & Cursor Home & 0 & 0 & 02 \\
\hline & Cursor Piscante & 0 & 0 & 0D \\
\hline & Cursor com Alternância & 0 & 0 & $0 \mathrm{~F}$ \\
\hline \multirow{2}{*}{$\begin{array}{l}\text { Sentido de deslocamento } \\
\text { cursor ao entrar com caractere }\end{array}$} & Para a esquerda & 0 & 0 & 04 \\
\hline & Para a direita & 0 & 0 & 06 \\
\hline \multirow{2}{*}{$\begin{array}{l}\text { Deslocamento da mensagem } \\
\text { ao entrar com caractere }\end{array}$} & Para a esquerda & 0 & 0 & 07 \\
\hline & Para a direita & 0 & 0 & 05 \\
\hline Deslocamento da mensagem & Para a esquerda & 0 & 0 & 18 \\
\hline sem entrada de caractere & Para a direita & 0 & 0 & $1 \mathrm{C}$ \\
\hline \multirow[t]{2}{*}{ End. da primeira posição } & primeira linha & 0 & 0 & 80 \\
\hline & segunda linha & 0 & 0 & $\mathrm{CO}$ \\
\hline
\end{tabular}

Figura 18 - Instruções de um LCD básico.

Fonte: (SILVA, 2006). 


\section{DESENVOLVIMENTO DO PROJETO MEDIDOR RESIDENCIAL INTELIGENTE}

\subsection{Projeto do Módulo Analógico A1}

Este módulo tem a função de colher amostras da tensão e corrente $A C$ (Alternate Current - Corrente Alternada) a serem medidas e converte-las em níveis de tensão DC (Direct Current - Corrente Contínua), que serão entregues às entradas analógicas do microcontrolador no módulo digital. A figura 19 ilustra o diagrama elétrico da etapa de medição de tensão AC. O circuito é constituído por um divisor de tensão que reduz a tensão para $5 \mathrm{~V}$ na saída quando a tensão de fase for $240 \mathrm{~V}$ na entrada do divisor. Em seguida tem-se um retificador de precisão formado por dois amplificadores operacionais, e a tensão retificada é então integrada por um filtro RC (GUSSOW, 2009).

O diodo Zener atua como um grampeador de tensão impedindo que a entrada analógica do microcontrolador do módulo digital seja danificada por sobre tensão (PERTENCE, 2003). Na saída deste bloco tem-se um nível de tensão contínua variando entre $0 \mathrm{~V}$ e $5 \mathrm{~V}$ que, é diretamente proporcional ao nível de tensão $\mathrm{AC}$ na entrada do bloco.

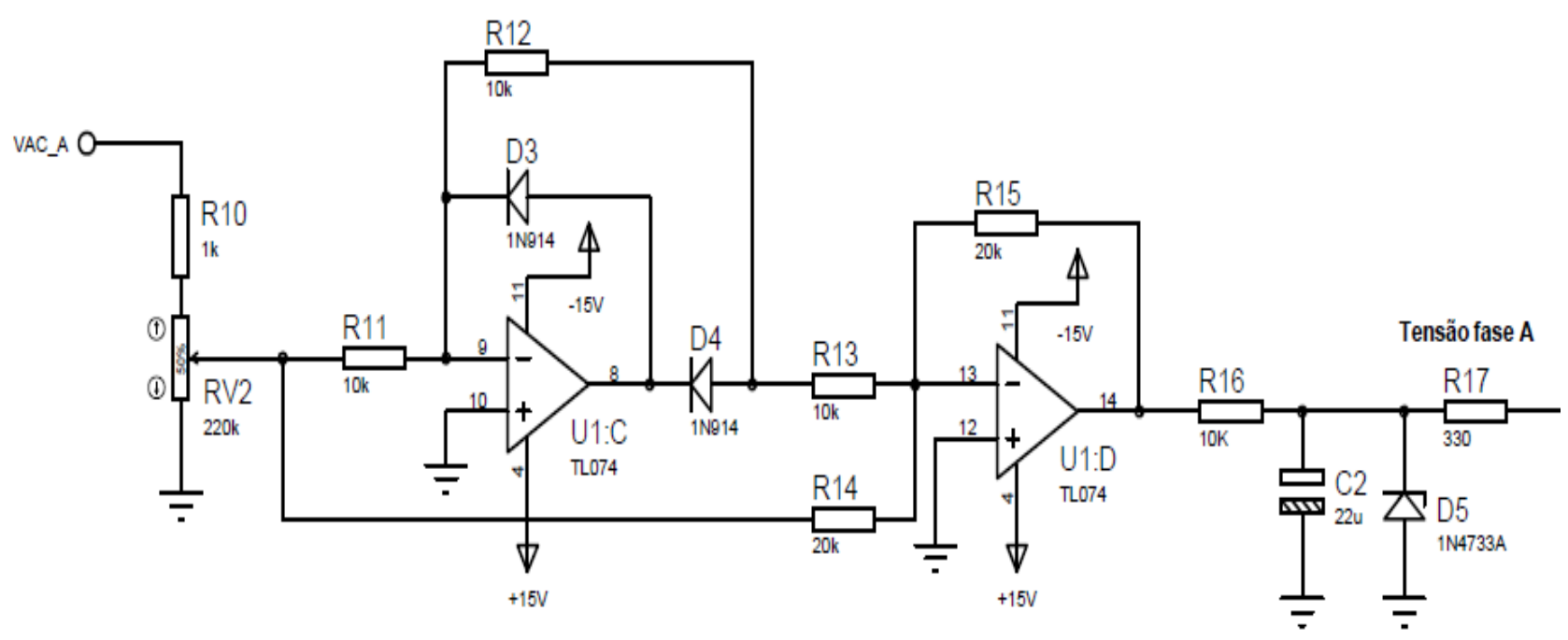

Figura19 - Diagrama elétrico da etapa desenvolvida para medir tensão AC.

Fonte: (Adaptado de BROW, 2001).

Após pesquisar os métodos para medir corrente elétrica AC é decidido usar como sensor um Transformador de Corrente (TC). Esta é a solução aplicada na maioria 
dos equipamentos de medição industriais e em todos os amperímetros do tipo "alicate" comerciais.

O transformador de corrente é construído enrolando uma bobina com 200 voltas de fio esmaltado de $0.5 \mathrm{~mm}^{2}$ sobre um núcleo formado por uma barra de ferro e um parafuso. O bloco que executa a medição de corrente AC é mostrado na figura 20. Pode-se notar que o circuito é muito similar ao módulo medidor de tensão, sendo que é adicionado mais um amplificador operacional para amplificar o nível de tensão entregue pelo TC ao retificador de precisão. O amplificador não inversor tem seu ganho definido pela equação (6) (BROW, 2001).

$$
E o=E i \times \frac{-R v 1+R 2}{R 1}
$$

$\mathrm{Na}$ saída deste bloco tem-se um nível de tensão contínua variando entre $0 \mathrm{~V}$ e 5V, diretamente proporcional ao nível de corrente AC em TC1 (BROW, 2001).

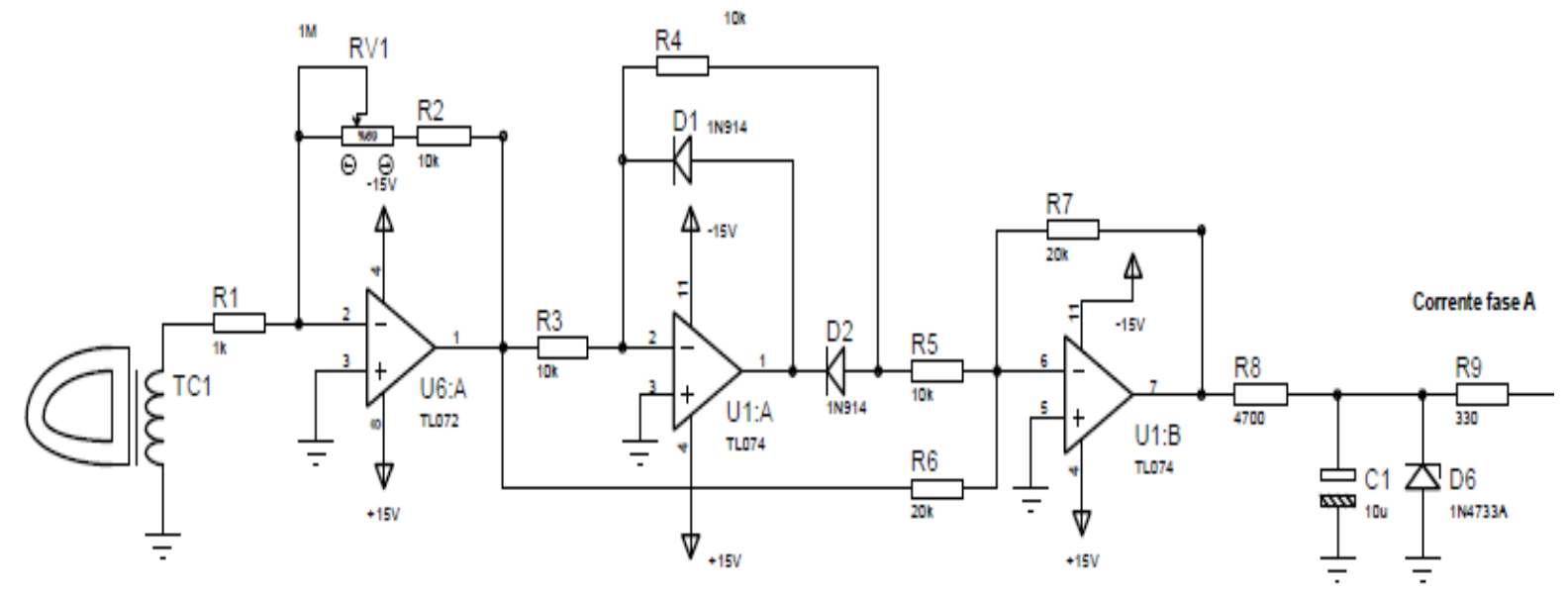

Figura 20 - Diagrama elétrico da etapa desenvolvida para medir corrente AC.

Fonte: (Adaptado de BROW, 2001).

\subsection{Elaboração do Módulo Digital D1}

O núcleo desse módulo é constituído por um micro controlador PIC 18F4620 que é um microcontrolador de 8bits, com 64kbytes de memória RAM, clock de até 40 $\mathrm{MHz}$, capacidade para executar até 10 milhões de instruções por segundo, 13 entradas analógicas de 10 bits de resolução, porta de comunicação serial síncrona SPI e I' ${ }^{2} \mathrm{C}$ (MICROCHIP, 2008). A figura 21 mostra o diagrama do módulo digital com seus diversos componentes. 
O sinal de tensão e corrente proveniente dos módulos analógicos são entregues as respectivas entradas analógicas, que fazem a conversão de analógico para digital $(A / D)$. Após a conversão, o resultado de cada entrada é salvo em uma variável do tipo double (16bits) do PIC (PEREIRA, 2010). Portanto, tem-se uma variável V (volts) e uma chamada I (ampare), e cada uma representa o valor instantâneo de tensão e corrente presente na entrada do medidor em um dado momento. Para obter o valor da potência aparente multiplica-se V por I.

Para calcular o fator de potência, é utilizado circuitos que detectam a passagem da tensão pelo "OV" quando então um contador de tempo é disparado e um detector da passagem da corrente por " $\mathrm{OA}$ " cessa a contagem, conhecendo o período da rede elétrica, assim pode-se então calcular a defasagem entre corrente e tensão da rede e determinar o fator de potência .

Um circuito de relógio de tempo real foi acrescentado ao circuito para registrar o horário e data das ocorrências e uma memória externa do tipo EEPROM (de Electrically-Erasable Programmable Read-Only Memory) é adicionada para o armazenamento dos dados de tensão, corrente e suporte para a interface ethernet. Ambos os chips estão interligados ao microcontrolador por uma rede ${ }^{2} \mathrm{C}$ (PEREIRA, 2010). Um display LCD e interruptores tipo tecla foram adicionados ao circuito para proporcionar integração "homem-máquina" local.
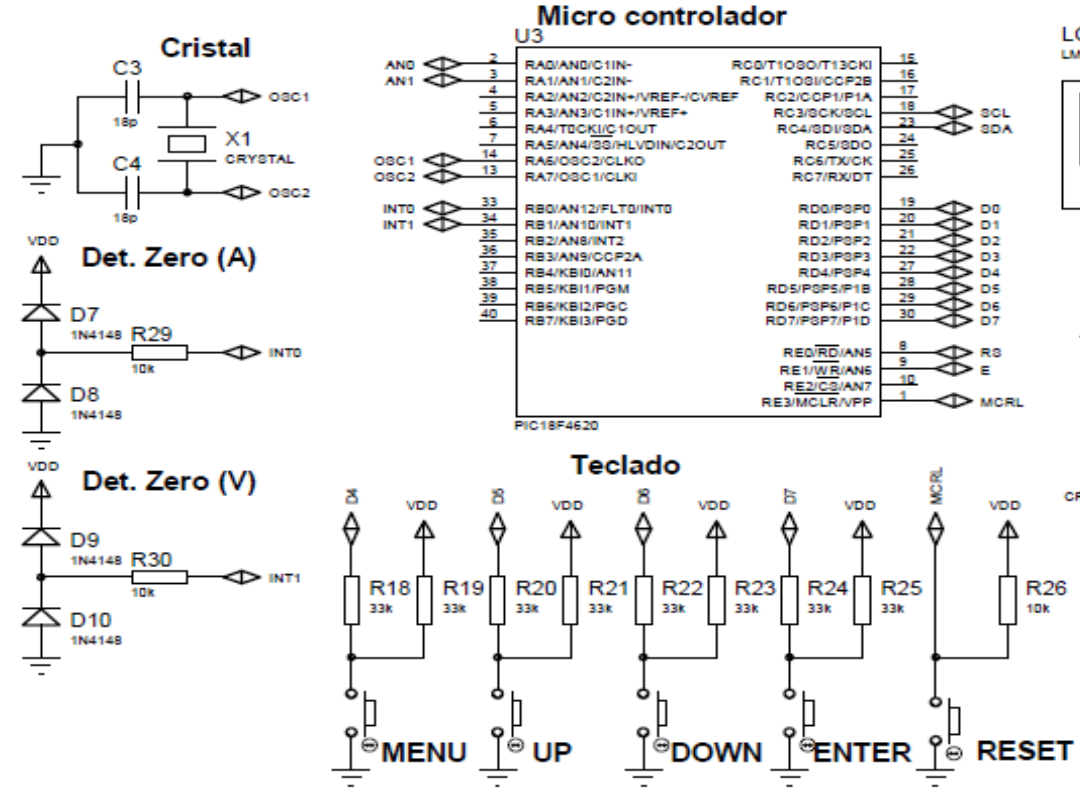

Figura 21 - Diagrama elétrico do módulo digital.

Fonte: (Adaptado de MICROCHIP, 2010).
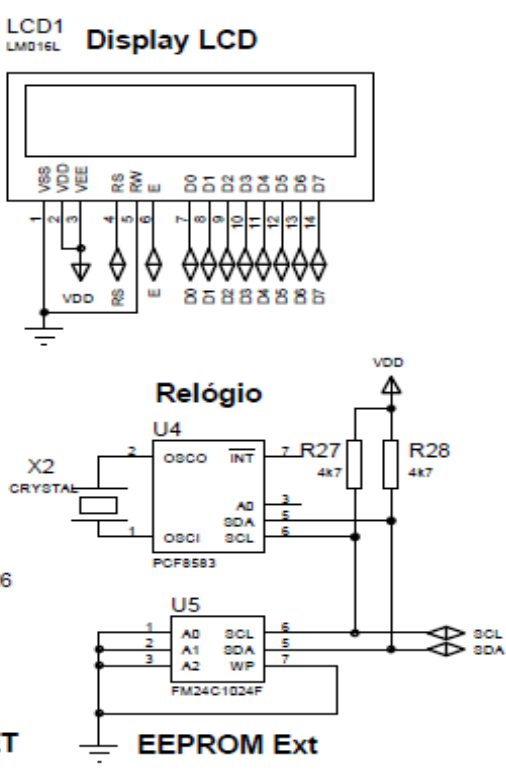


\subsection{Desenvolvimento do Módulo de Comunicação C1}

No cenário atual, a internet é a rede de dados mais importante e utilizada, nesse contexto, o projeto prevê a comunicação com uma rede de computadores local do tipo ethernet e o PIC 18F4620 é um micro controlador adequado por possuir memória suficiente para suportar o tamanho de uma pilha TCP/IP (Transmission Control Protocol - Protocolo de Controle de Transmissão / Internet Protocol Protocolo de Interconexão). Entretanto é necessário um controlador de ethernet, onde o ENC28J60 é utilizado. Ele é fabricado pela Microchip e possui uma relativa facilidade para integração com o PIC 18F4620. A figura 22 ilustra a interligação com o microcontrolador. A comunicação entre os dois é serial síncrona sendo que o PIC18F4620 assume a posição de "mestre" e o ENC28J60 é o "escravo" (MICROCHIP, 2010).

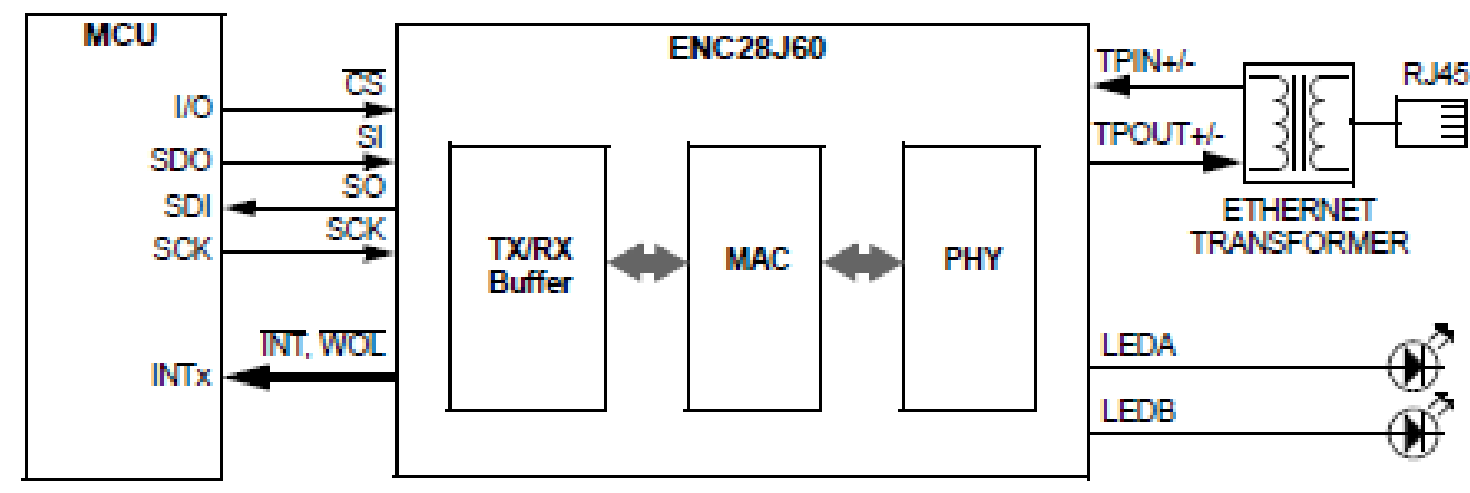

Figura 22- Diagrama de interligação do controlador ethernet.

Fonte: (Adaptado de MICROCHIP, 2010).

\subsection{Desenvolvimento do Módulo de Acionamento de Cargas AC1}

Este módulo tem a função de desligar cargas que excedam valores pré-definidos, por exemplo, o chuveiro elétrico, que será desligado em caso de funcionamento por tempo superior ao definido.

Também é possível liberar o funcionamento dos circuitos de iluminação apenas em horários e por tempo definidos. O controle das cargas é feito diretamente no quadro de medição por meio de relés acionados por saídas digitais do microcontrolador. O chuveiro pode ser controlado através da instalação de uma válvula de acionamento elétrico em série com a tubulação 
hidráulica. Esta válvula é normalmente encontrada em máquinas de lavar. Quando o chuveiro é acionado, o aumento no consumo é detectado pelo microcontrolador que irá monitorar o tempo de uso do chuveiro. Se o tempo ultrapassar o valor pré definido o microcontrolador irá desligar a saída digital conectada ao relé que alimenta a bobina solenóide da eletro válvula do circuito hidráulico, fechando a válvula e conseqüentemente desligando o chuveiro. $O$ circuito desenvolvido para o módulo de acionamento de cargas é mostrado na figura 23.
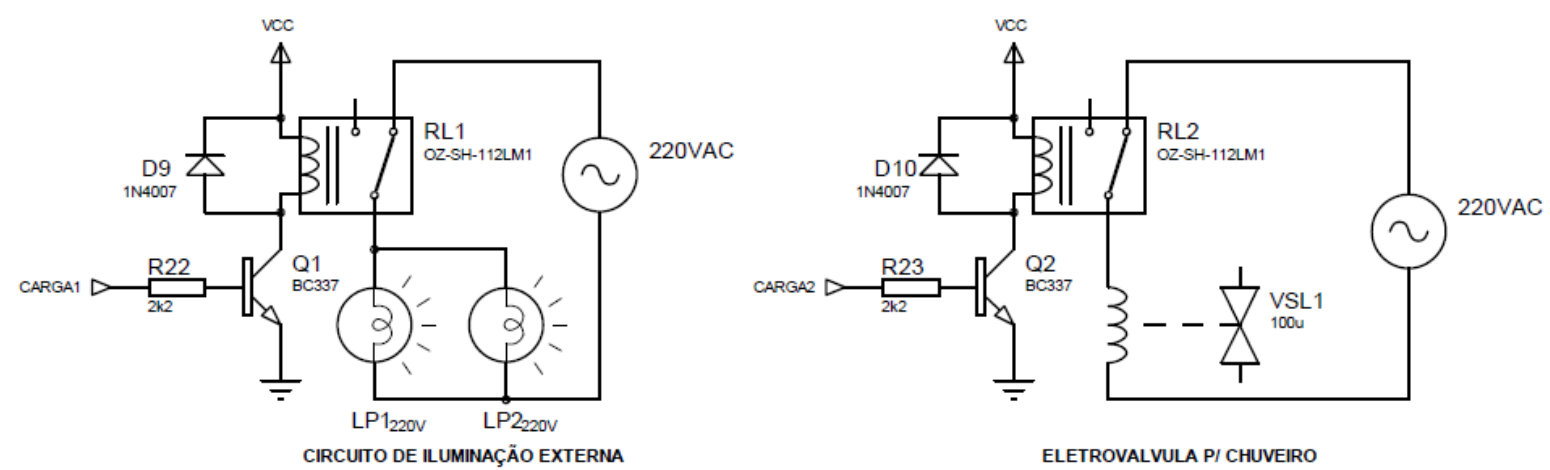

Figura 23- Diagrama elétrico da etapa de acionamento de cargas externas.

A maior vantagem no uso deste tipo de válvula está no custo, bem menor que o valor de um relê com a capacidade de ruptura para um circuito de chuveiro. A válvula também evita o desperdício de água, outro recurso natural precioso. 


\section{RESULTADOS}

O Transformador de Corrente é construído como mostrado na figura 24. Para analisar as características do TC (Transformador de Corrente) é necessário montar um circuito de prova com carga variável, onde a corrente varie desde $0 \mathrm{~A}$ a $15 \mathrm{~A}$. Este circuito é construído com um balde plástico com capacidade de $15 \mathrm{l}$ que é preenchido com uma solução de água e sal de cozinha. Dois eletrodos de chapas metálicas são ligados aos pólos da rede elétrica através de um disjuntor para proteção contra sobrecargas e curto circuitos e mergulhados na solução. Durante os testes de medição foi usado um alicate amperímetro digital comercial marca ICEL modelo AD9010 mostrado na figura 25.

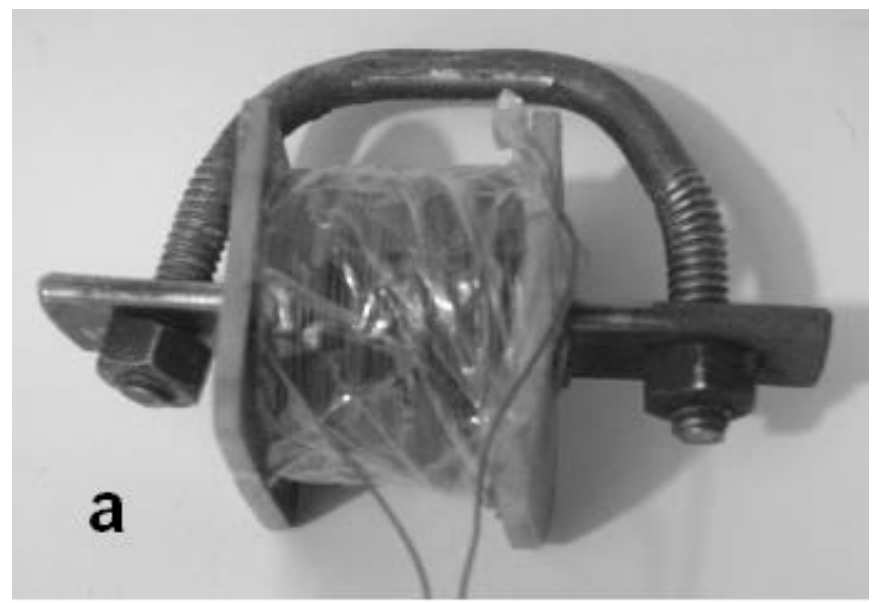

Figura 24 - Fotografia do TC experimental desenvolvido..

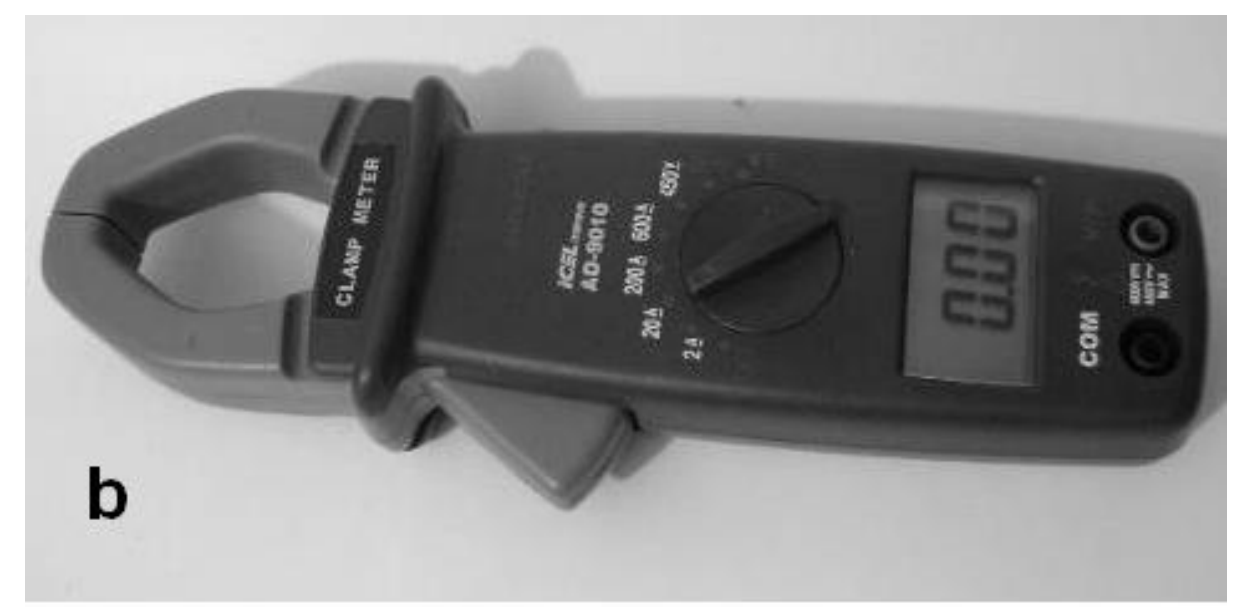

Figura 25 - Fotografia do Amperímetro Digital Alicate usado.

O circuito pode ser visto na figura 26 , e a corrente na carga varia em função da profundidade e distância entre eletrodos mergulhados na solução. A figura 27 mostra 
o gráfico dos valores de tensão sobre o resistor de carga do TC em função da corrente no circuito medida com o alicate amperímetro, mostrando a linearidade entre tensão e corrente.

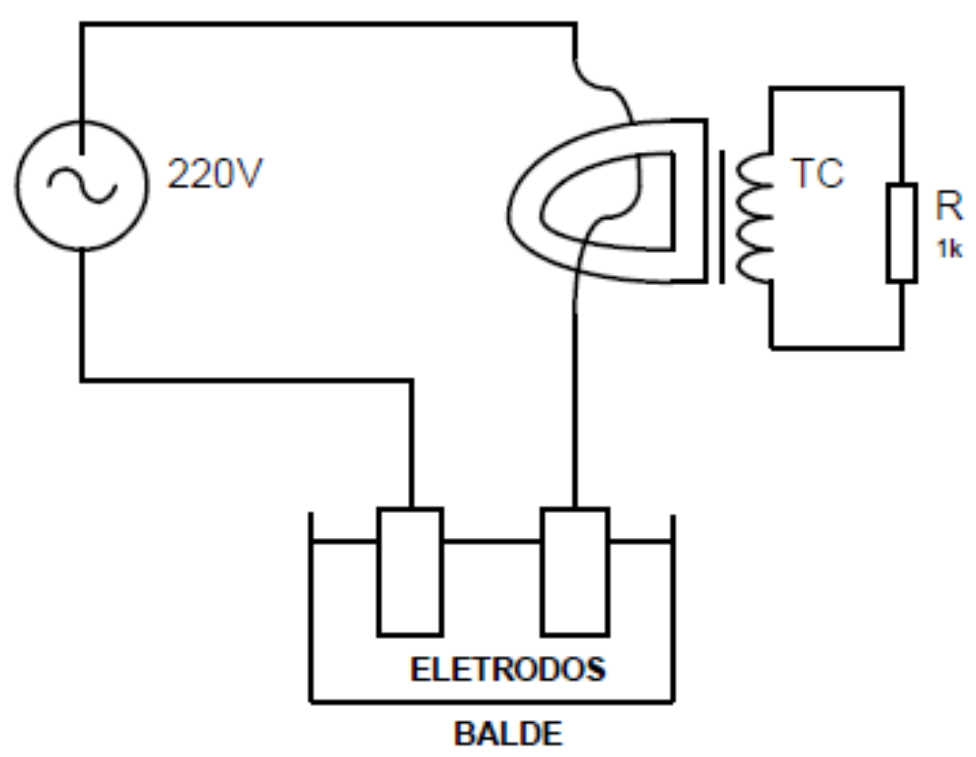

Figura 26 - Circuito de carga usado durante as medições.

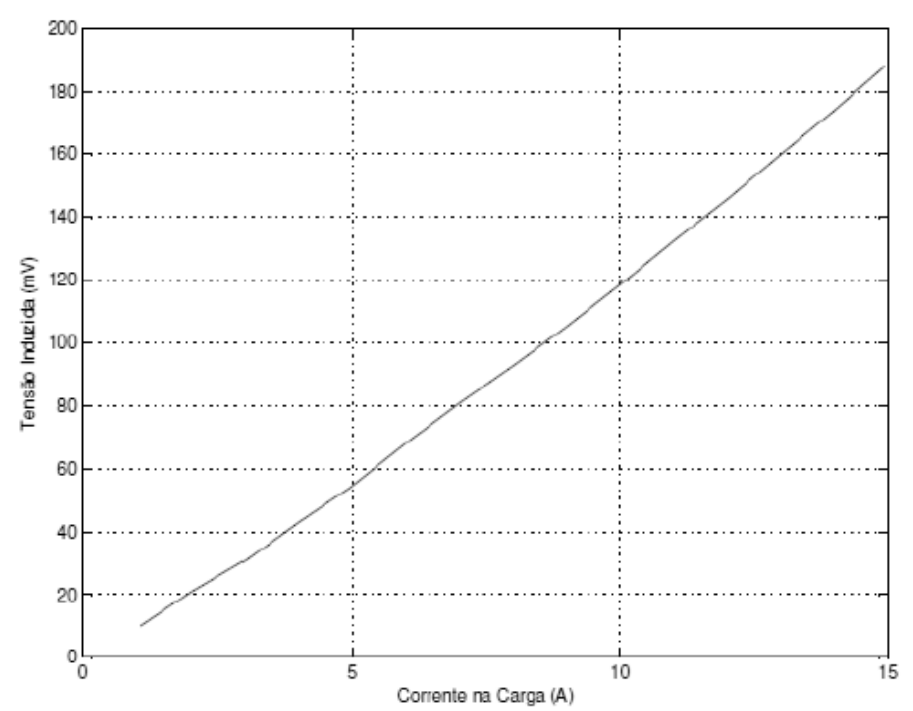

\begin{tabular}{|c|c|}
\hline $\mathrm{mV}$ & $\mathrm{A}$ \\
\hline 10 & 1.08 \\
\hline 21 & 2.04 \\
\hline 31 & 3.03 \\
\hline 43 & 4.00 \\
\hline 54 & 4.96 \\
\hline 69 & 6.07 \\
\hline 81 & 7.02 \\
\hline 93 & 8.03 \\
\hline 105 & 8.99 \\
\hline 119 & 10.04 \\
\hline 133 & 11.05 \\
\hline 146 & 12.03 \\
\hline 160 & 13.01 \\
\hline 174 & 14.01 \\
\hline 188 & 14.95 \\
\hline
\end{tabular}

Figura 27 - Curva de transferência do TC.

A figura 28 e 29 mostra as fotografias das placas do protótipo. Podem-se ver no display de cristal líquido a apresentação das medidas instantâneas de tensão, corrente e potência (figura 28) e o registro do acumulador da potência total consumida pela residência (figura 29). A fonte de alimentação é mostrada na figura 30, foi adquirido provisoriamente um módulo comercial de comunicação ethernet como mostra a figura 31 . 


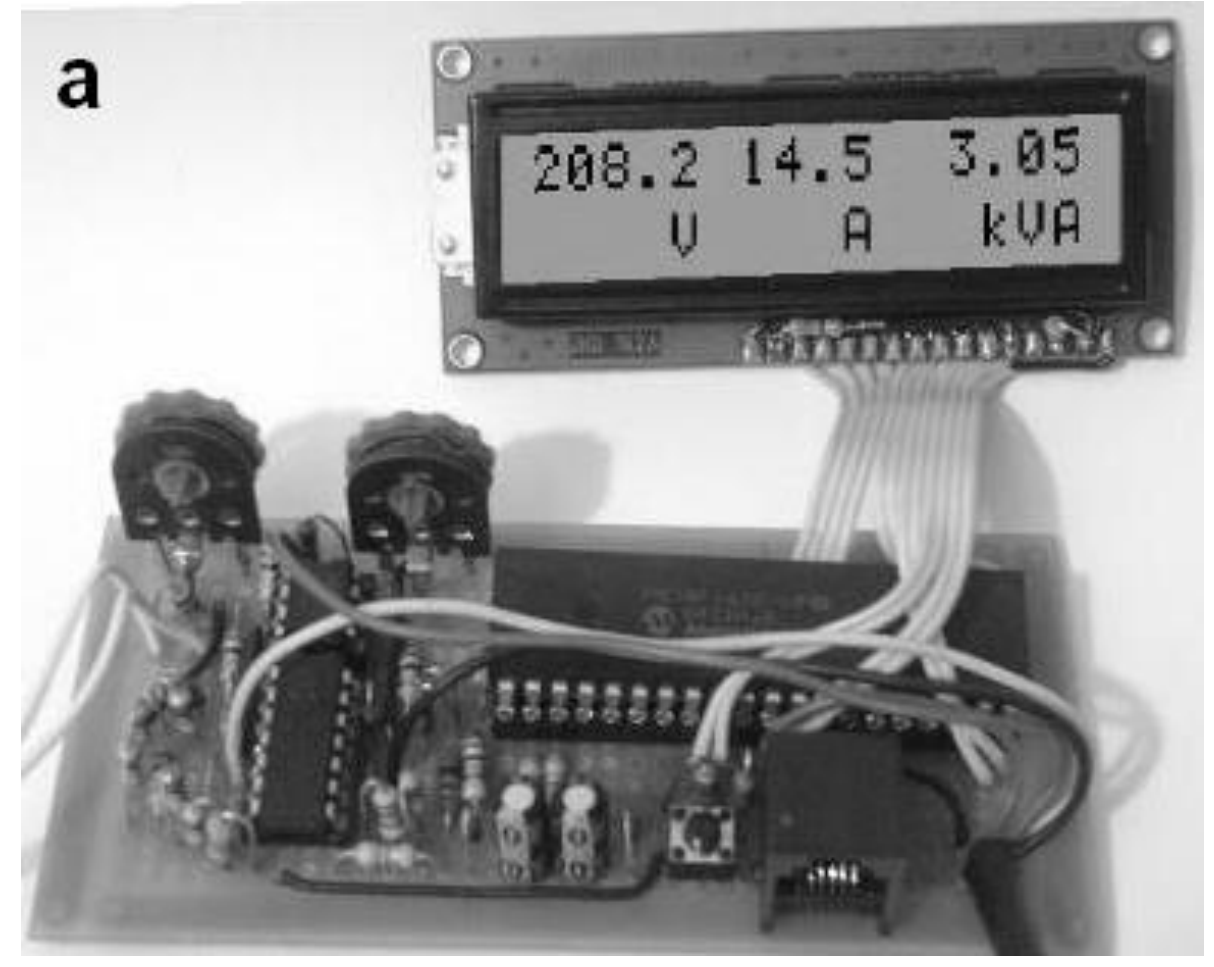

Figura 28 - Fotografia da tela de medição.

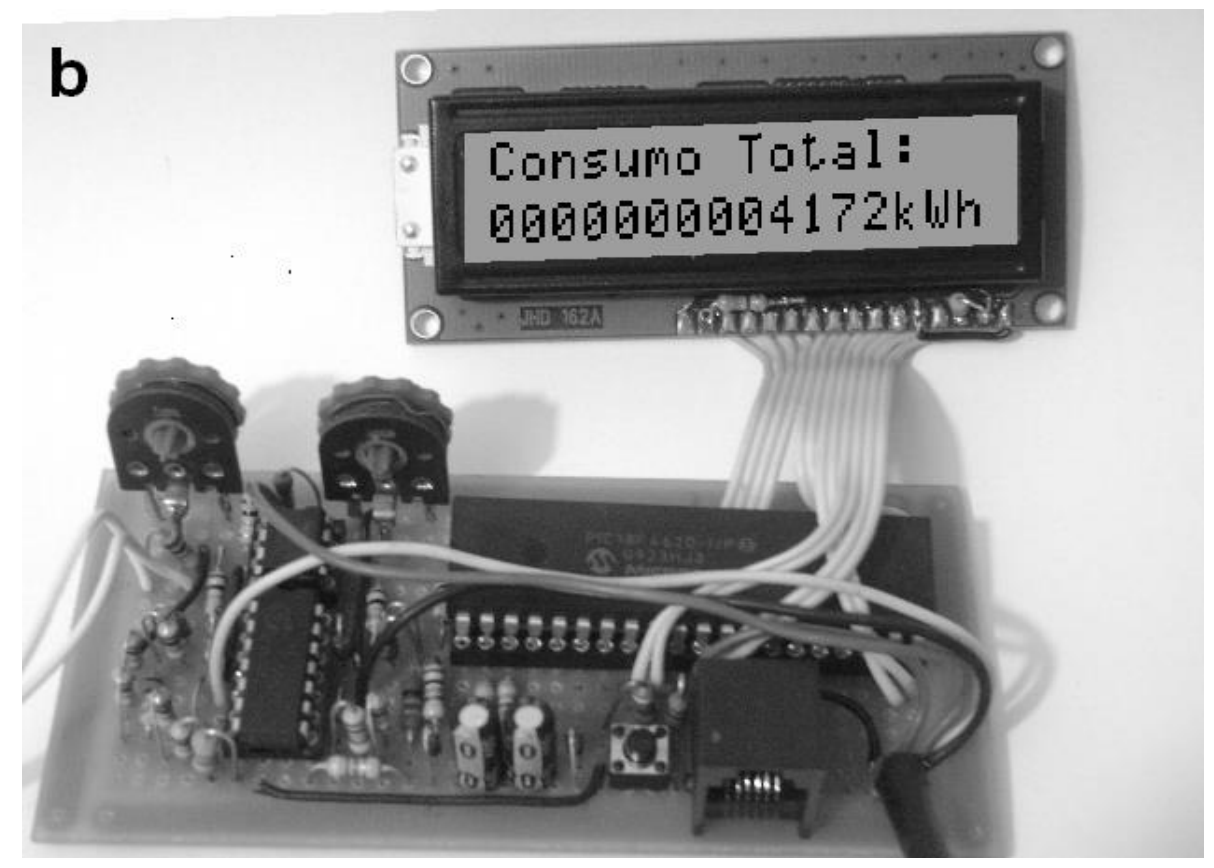

Figura 29 - Fotografia da tela de medição. 


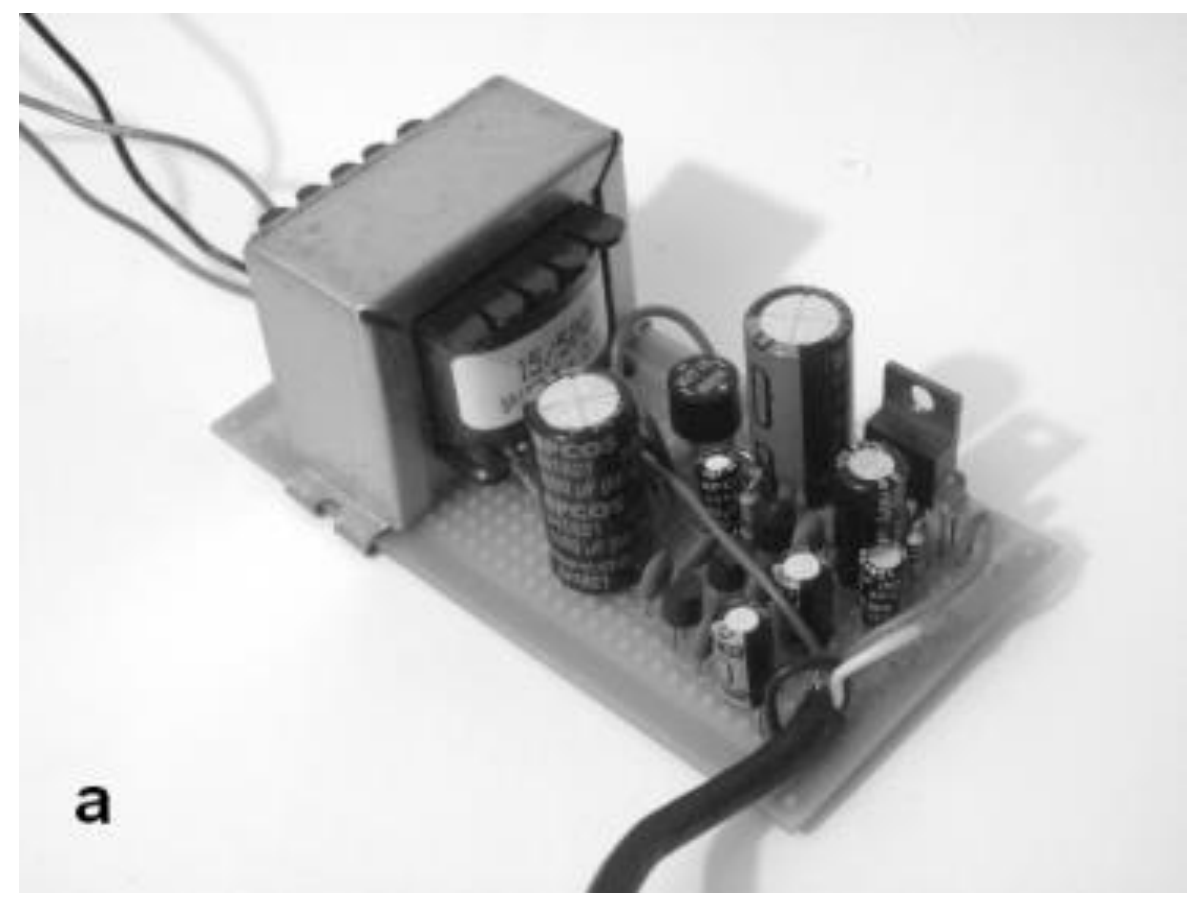

Figura 30 - Fotografia da fonte de alimentação.

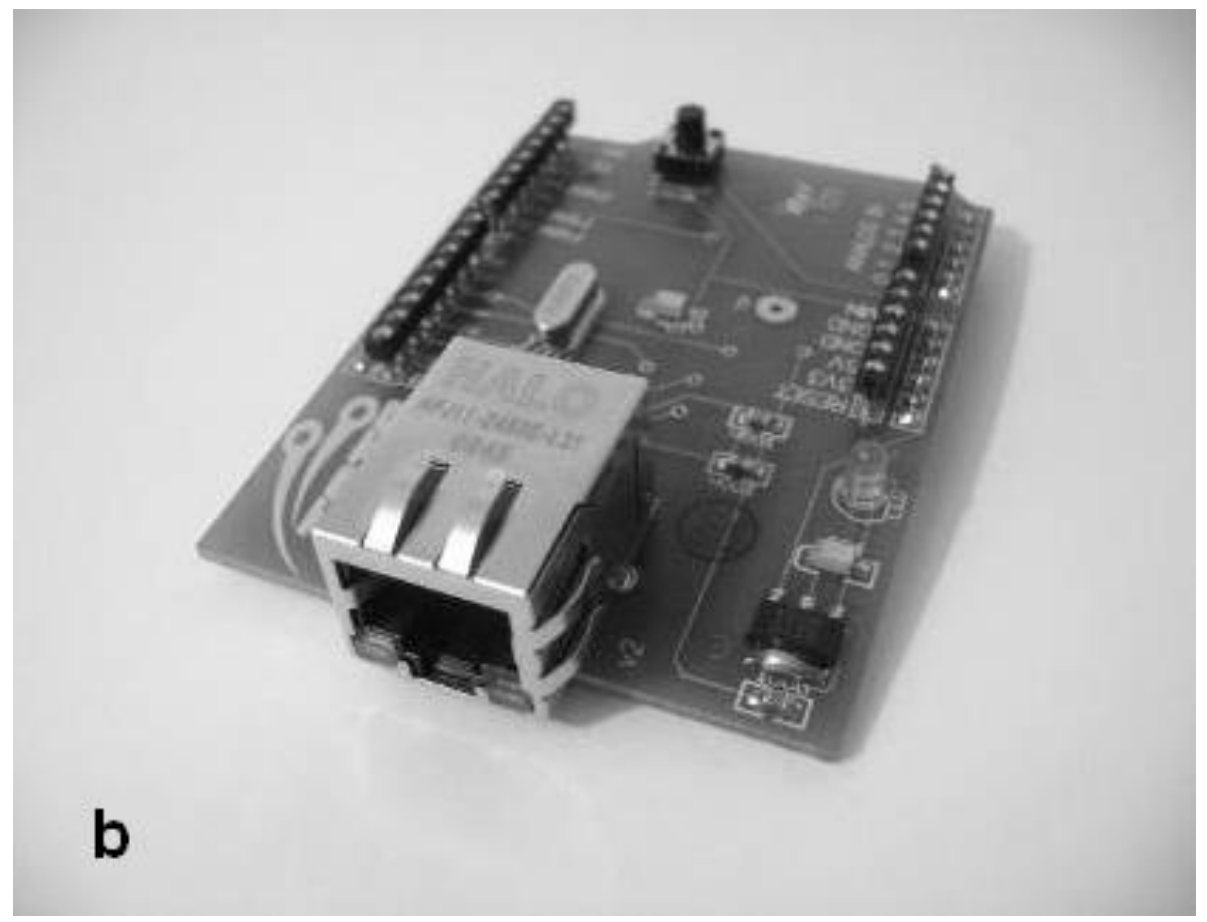

Figura 31 - Fotografia do módulo de ethernet.

O código do firmware do PIC é escrito em linguagem $C$ e a ferramenta usada no desenvolvimento foi o compilador MikroC Pro da Mikroelektronika em sua versão de demonstração (MIKROC, 2010). Na figura 32 é mostrada parte das rotinas de leitura 
e conversão das entradas analógicas de tensão e corrente, o cálculo da potência e a apresentação das leituras no display LCD.

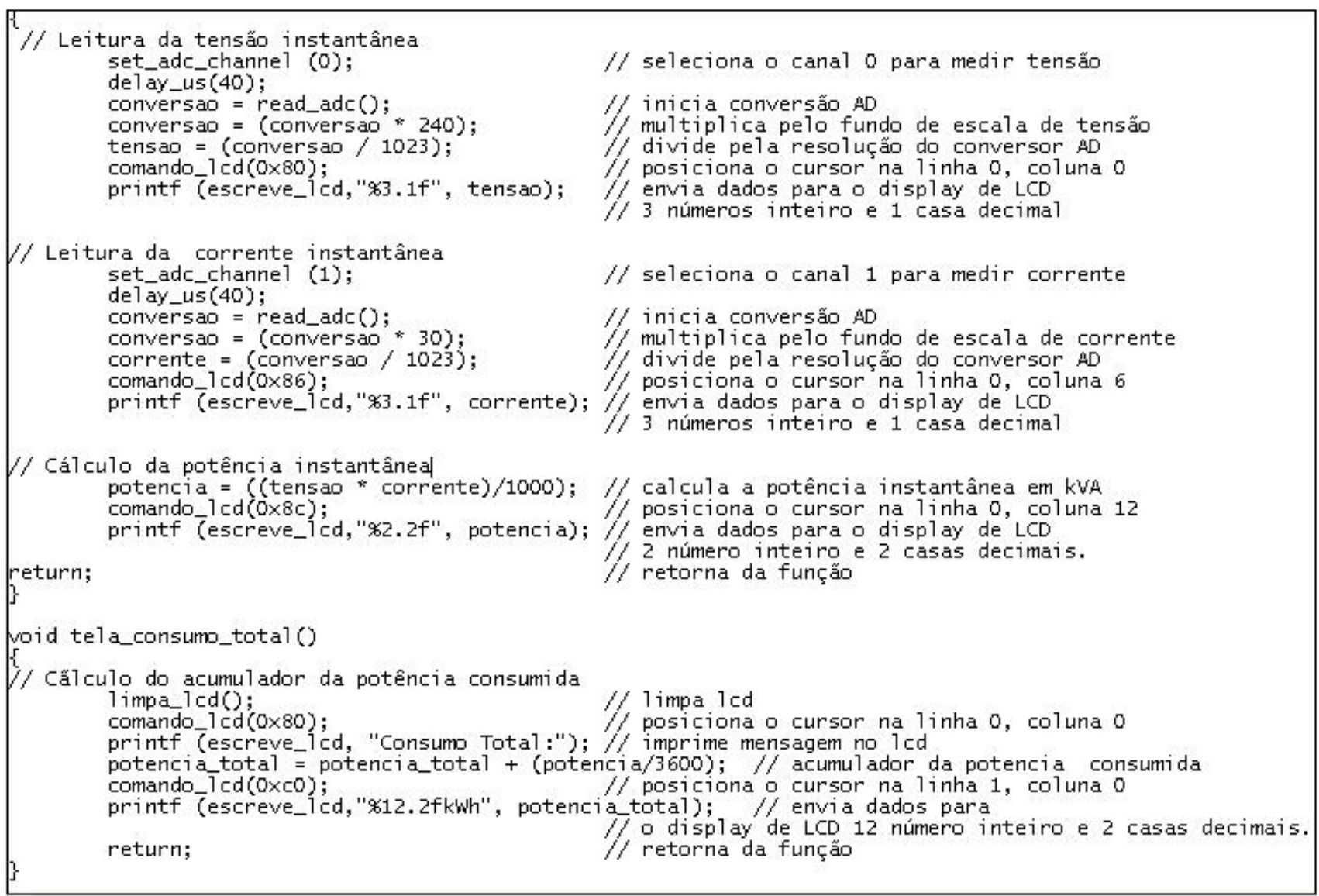

Figura 32 - Código em linguagem C escrito no compilador MikroC Pro Demo. 


\section{CONSIDERAÇÕES FINAIS}

Os resultados obtidos demonstram a viabilidade e relevância do projeto no que se refere à questão de medição, controle e redução do desperdício de energia. Os módulos de medição e de coleta de dados foram concluídos e testados. O projeto apresenta uma visão voltada para a sustentabilidade possibilitando ao usuário comum controlar seus gastos com energia e ainda traçar metas de consumo a serem cumpridas, conforme seu desejo de consumo mensal e orçamento. Nesse cenário, o Medidor Residencial Inteligente de Energia elétrica contribui para o combate ao desperdício de energia elétrica, permitindo sua redução e detecção de fuga de corrente quando existir. O projeto está na fase final de testes do software de geração de relatórios, eletronicamente todos os módulos foram concluídos e realizando medidas corretamente. As medidas foram compradas com instrumentos portáteis medidores de corrente, tensão e apresentaram medidas com precisão e sem erro.

O projeto pode ser aplicado ao programa do governo federal, "Minha Casa Minha Vida", que consiste na construção de casas para população carente, mediante financiamento da Caixa Econômica federal. O projeto apresenta um custo final de 185 reais. A proposta de sua utilização no referido projeto do governo poderá contribuir para um planeta melhor, visando um consumo racional e possibilitando a detecção de fuga de corrente que prova desperdícios.

Os sistemas atuais para medição de energia elétrica baseiam-se em medidas puras de corrente, tensão e energia consumida em kwh. O projeto apresentado além das medições convencionais realiza a medida de fuga de corrente, disponibiliza visualizações em vários dispositivos tais como, display de cristal liquido e via computador. Ressalta-se ainda que o circuito desenvolvido apresenta um dispositivo de proteção em caso de curto-circuito em seus sistema.

Se analisarmos sua funcionalidade e objetivos, o projeto proposto não é considerado de luxo, pois irá proporcionar redução de gastos desnecessários e desperdícios, contribuindo com a redução do consumo elétrico. Isso implicará em uma redução e otimização na geração de energia elétrica, beneficiando o meio ambiente, pois $90 \%$ da energia no Brasil são provenientes de hidrelétricas, segundo dados da ANEEL.

Uma dos benefícios oferecidos pelo Medidor Residencial em prol do cliente e a verificação real de consumo de energia e possibilidade de controlar 
automaticamente o tempo de ativação e desativação de suas cargas, em sua residência. Caso exista fuga de corrente elétrica nas instalações da residência do cliente, o medidor identifica e sinaliza falha nas instalações da rede elétrica interna. Porém, apesar do protótipo ter funcionado é necessário dar continuidade no projeto, pois se faz necessário o completo desenvolvimento do software do sistema. Atualmente o protótipo está em fase de testes e e em desenvolvimento do software para geração e tratativa das medias elétricas via rede IP (Internet Protocol)

\section{REFERÊNCIAS}

ANEEL, Agência Nacional do Petróleo-ANP. Brasília, 1999. 432p. 23cm. Cap. 1 e 2. p. 20-263. ISBN 85-87491-02-04.

BRASIL, MINISTÉRIO DAS MINAS E ENERGIA. Balanço energético nacional 1999, Brasília, 1999, 153p. ilustradas. 29,7 cm. p.43. ISS0101-6636.

BROW, Thomas R., CARTER, Bruce. Handbook of operational amplifier applications, TEXAS Instruments, 2001. Disponível em:<http://focus.ti.com/general/docs/litabsmultiplefilelist.tsp?literatureNumber=sboa0 92a >Acesso em: Jul. 2010.

BOYLESTAD, Robert L. Dispositivos Eletrônicos e Teoria de Circuitos, 6aㅡ Ed., Editora LTC, 1999.

Comissão de Serviços Públicos de Energia. Usinas Termelétricas de Pequeno Porte no Estado de São Paulo. São Paulo:2001. 427p.

Desperdício de Energia no Brasil, acesso em: http://diariodonordeste.globo.com/materia .asp?codigo=558404, Acesso em: dez 2010.

GORE, Albert. Uma Verdade Inconveniente, Manole, 2006.

GONÇALVES, Rinaldo Câmara. Curso PIC3: Linguagem C, 2ª Revisão, São Paulo: LabTools Mosaico Didatic Division, 2008.

IBGE,

http://www.ibge.gov.br/home/estatistica/indicadores/precos/inpc ipca/notatecnica022 001.shtm, Acesso em : dez 2010. 
LANDO, Roberto A; ALVES, Serg Rios; Amplificador Operacional. 4ª Ed., Editora Érica, 1983.

LEITÃO, R., RÉGIS, P. A , Luiz, A. , Medidores de Corrente Elétrica para Detecção de Fuga em Componentes do Sistema Elétrico, IFCE-Instituto Federal do Ceará, 2005.

MIZRAHI, Victorine Viviane. Treinamento em Linguagem C: módulo 1 e 2, São Paulo: Pearson Prentice Hall, 2007. Anhanguera Educacional, Programa do Livro Texto.

MARTINS, A.R.S., ALVEAL, Carmem, SANTOS, E.M. et al. Eficiência energética: integrando usos e reduzindo desperdícios. Agência Nacional de Energia Elétrica, 1999.

SILVA, Renato A. Programando Microcontroladores PIC Linguagem "C". 1르., Editora Ensino Profissional, 2006.

MICROCHIP, PIC18F4620 e ENC28J60 Datasheet, Disponível em: $<$ http://www.microchip .com /wwwproducts/Devices.aspx?dDocName=en010304>. Acesso em: Jul. 2010.

SOUZA, David José de. Conectando o PIC 16F877A: Recursos Avançados, 4a Ed., São Paulo: Érica, 2007.

SOUZA, David José de. Desbravando o PIC: ampliado e atualizado para PIC 16F628A, 11를., São Paulo: Érica, 2007.

PEREIRA, Fábio. Microcontrolador PIC18 Detalhado, 1르 Ed., São Paulo: Érica, 2010.

PEREIRA, Fábio. PIC: Programação em C, 7ª Ed., São Paulo: Érica, 2007.

PERTENCE, ANTONIO. JR, Eletrônica Analógica - Amplificadores Operacionais e Filtros Ativos, 6ㄹ Edição. São Paulo: Bookman, 2003. 